\title{
Digital Healthcare Technologies: Modern Tools to Transform Prosthetic Care
}

\begin{tabular}{|r|l|}
\hline J ournal: & Transactions on Neural Systems \& Rehabilitation Engineering \\
\hline Manuscript ID & TNSRE-2020-00475 \\
\hline Manuscript Type: & Paper \\
\hline Date Submitted by the & O6-Aug-2020 \\
\hline Complete List of Authors: & $\begin{array}{l}\text { Cabrera, Isaac; University of California San Diego, Mechanical and } \\
\text { Aerospace Engineering; University of California San Diego, } \\
\text { Pike, Trinity; University of California San Diego, Mechanical and } \\
\text { Aerospace Engineering } \\
\text { McKittrick, J oanna; University of California San Diego, Mechanical and } \\
\text { Aerospace Engineering } \\
\text { Meyers, Marc; University of California San Diego, Mechanical and } \\
\text { Aerospace Engineering } \\
\text { Rao, Ramesh; University of California San Diego, Calit2 } \\
\text { Lin, Albert; University of California San Diego, Calit2 }\end{array}$ \\
\hline
\end{tabular}

\section{SCHOLARONE ${ }^{\text {MW }}$ \\ Manuscripts}

This work has been submitted to the IEEE for possible publication. Copyright may be transferred without notice, after which this version may no longer be accessible

This manuscript contains images that are subject to additional copyright restrictions. Please consult the respective publishers for information on reproduction and fair usage of the figures. 


\title{
Digital Healthcare Technologies: Modern Tools to Transform Prosthetic Care
}

\author{
Isaac A Cabrera*, Trinity C. Pike, Joanna M. McKittrick, \\ Marc A. Meyers, Ramesh R. Rao, Fellow, IEEE, Albert Y. Lin
}

\begin{abstract}
Digital healthcare technologies are transforming the face of prosthetic care. Millions of amputees around the world do not currently have access to any form of prosthetic healthcare. However, digital technologies provide a promising solution. Digital healthcare technologies have the potential to augment the range and efficiency of prosthetists so they can reach more patients. These technologies will enable affordable prostheses to be built on a scale larger than currently possible with today's clinical practices. In this paper, we explore the social aspects of amputation as a global issue, describe current practices for designing and manufacturing prosthetic sockets, and examine shifting trends towards virtual care models. Importantly, we assess the technologies used in these virtual health workflows to understand their critical needs. Large technological gaps need to be overcome in order to enable the mass production and distribution of prostheses digitally. However, recent advances in computational methods and CAD/CAM technologies are bridging this gap faster than ever before. We foresee that these technologies will return mobility and economic opportunity to amputees on a global scale in the near future.
\end{abstract}

Index Terms-Prosthetic, Digital Healthcare Technologies, Virtual Design Workflows, Telemedicine, CAD/CAM

\section{INTRODUCTION}

\section{A. Amputation as a Global Issue}

The loss of any limb is a traumatic event that can dramatically hinder an amputee's ability to live a healthy, productive, and independent life. The World Health Organization estimates that there are between 35 and 40 million amputees around the world [1]. Amputation does not just impact developing nations, but also the United States, where 185,000 Americans lose their limbs every year [2]. Limb loss affects every country around the world, but the causes vary dramatically.

For instance, in developed nations such as the United States, diabetes is the leading cause of amputations. Diabetes can increase a patient's risk of needing an amputation by a factor of 25 and is expected to affect 590 million people by 2030 [3]. Humanitarian crises such as the 2010 Haiti earthquake, or the civil war in Sierra Leone (1991-2002), led to a significant increase in the number of amputees in both countries [3].

The first two authors contributed equally to this work. ${ }^{*}$ Asterisk denotes corresponding author.

Isaac A Cabrera*, Trinity C. Pike, Joanna M. McKittrick, and Marc A. Meyers are with the Department of Mechanical and Aerospace Engineering, University of California San Diego, La Jolla, CA 920930411, United States (*email: iacabrer@eng.ucsd.edu.)

Albert Y. Lin and Ramesh R. Rao are with the California Institute for Telecommunications and Information Technology (Calit2), La Jolla, CA 92093, United States
Motor vehicle accidents are another major cause of amputation in the developing world [4]. Importantly, trauma resulting from the loss of a limb causes many amputees to struggle with depression while attempting to resume everyday activities [5]. Globally, the largest obstacle to amputees recovering from limb loss is the lack of access to quality, affordable prostheses.

"Prosthetics are assistive [medical] devices that restore function to an amputee following major limb loss" [6]. Amputees face systemic problems related to disability, but prosthetic limbs can empower amputees to overcome these barriers. Prosthetic limbs enhance mobility, which in turn: enables access to education, employment, and health care; alleviates poverty; and combats discrimination. Only between 5 and 15 percent of amputees worldwide use a prosthetic limb [1]. Both social and economic factors limit access to proper treatment and affordable, quality prostheses.

\section{B. Economic Impact of Amputation and Prostheses}

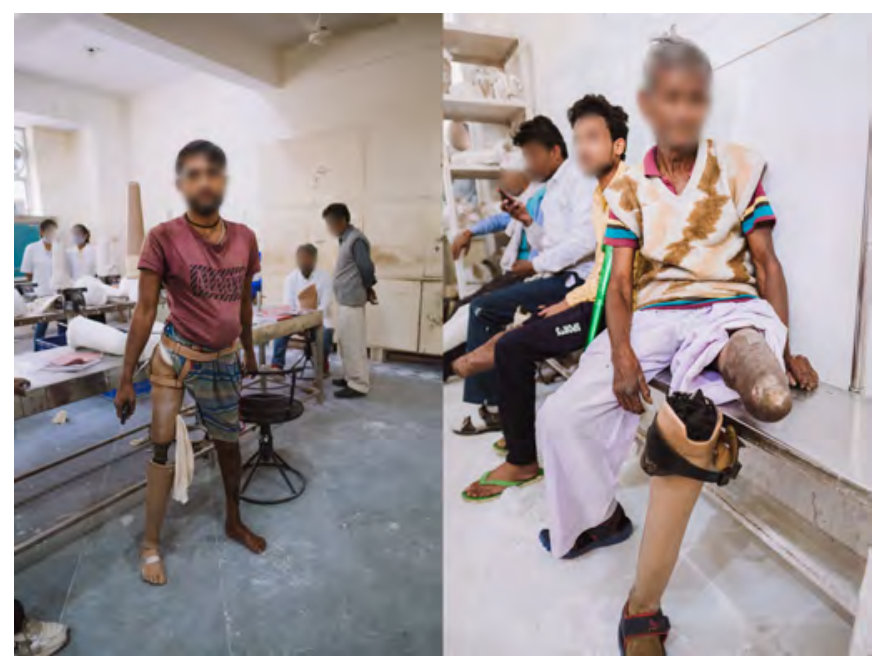

Fig. 1. Amputees receiving affordable prosthetic healthcare from the Bhagwan Mahaveer Viklang Sahayata Samiti (Jaipur Foot) clinic in Jaipur, India.

The economic effects of amputation significantly impact amputees in low-income countries. In these nations, disability causes poverty and often, poverty exacerbates disability [5]. $80 \%$ of the disabled population worldwide lives in low-income countries, with fewer than 3\% having access to necessary rehabilitation services [7]. In nations such as Sierra Leone, amputees often resort to begging in order to cover basic living needs [5]. The lack of access to affordable prostheses will 
only become a greater problem in the near future. Recent projections anticipate that the amputee population will double by 2050 [8], [9]. The disconnect between need and access to prosthetic care creates a relentless cycle of poverty that must be addressed on an international scale.

A study by David Blough [10] estimated that lifetime prosthetic costs for a unilateral lower limb amputee could range from $\$ 0.5$ to $\$ 1.8$ million in the United States. Estimates from the Worcester Polytechnic Institution [11] indicate that prices depend on the level of activity provided by the prosthetic device. For a minimally serviceable below-knee prosthesis, the estimated cost is between $\$ 5000-\$ 7000$ in the United States. For a prosthetic leg capable of being used for running, the estimated cost is between $\$ 12,000-\$ 15,000$.

The high costs of these prosthetics severely contrast with the limited budget available to most amputees. The International Committee of the Red Cross evaluated that $\$ 100$ was the maximum affordable cost for low income countries [12], [13]. Jaipur Foot in India has been very successful at meeting this challenge, and currently delivers prosthetic limbs at an average cost of $\$ 50$ [14]. They are able to deliver their prosthetic limbs to amputees free of charge to amputees due to generous government and external support (Fig. 1).

\section{Bringing Prosthetic Technology to the Developing World}

In addition to economic barriers, the scarcity of local clinics makes it difficult for amputees to actually be fitted with a prosthesis. Traveling to and staying at a clinic for treatment can impose large costs beyond medical fees [1]. Low income countries have few prosthetists and even fewer programs to train them. The small number of clinics not only lack proper resources, but are also critically understaffed. For example, at the Holy Family Centre in Monze, Zambia, the workshop is staffed by two technicians who take three to four days to manufacture one prosthesis [3].

In India, Jaipur Foot has grown to a total of 23 clinics [14]. However, these clinics are primarily concentrated in urban zones, limiting access for amputees in rural areas. To alleviate the shortage of clinics and prosthetists, more effective healthcare networks must be developed on a larger scale. Future systems must consider the complex requirements of prosthetic care as well as the socioeconomic factors of disability. Measures must be taken to increase disability education and awareness, decrease the cost of services, and expand the availability of prosthetic services. If these measures are successfully implemented, access to prosthetics will give amputees the opportunity to overcome systemic barriers and live productive, independent lives [5], [15].

\section{Current Design and Clinical Practice of PROSTHETIC SOCKETS}

\section{A. The Clinical Setting}

Modern prosthetic care centers around a clinical setting. The current manufacturing process requires an in-person consultation with a clinician to properly fit and align a prosthesis. While most of the components in a prosthesis can be mass produced, the prosthetic socket (or limb-prosthesis interface) requires specialized knowledge to manufacture and must be tailored specifically to each end user. Designing and manufacturing custom prosthetic sockets for every amputee is the single largest bottleneck to affordable prosthetic care.

A functional and safe prosthetic effectively transfers forces from the residual limb to the prosthesis while sustaining comfort and fit [16]-[18]. Prosthetists maintain quality standards by considering design requirements such as: maximizing weight-bearing surface area, minimizing friction, maintaining alignment, and stabilizing suspension to limit lever-arm effects [15], [19], [20]. Prosthetists also consider factors such as activity level and financial burden when shaping a custom socket [21], [22]. The prosthetic should seamlessly integrate into everyday activities, withstand wear and tear over time, and maintain the comfort of the user [23].

\section{B. The Prosthetic Manufacturing Process}

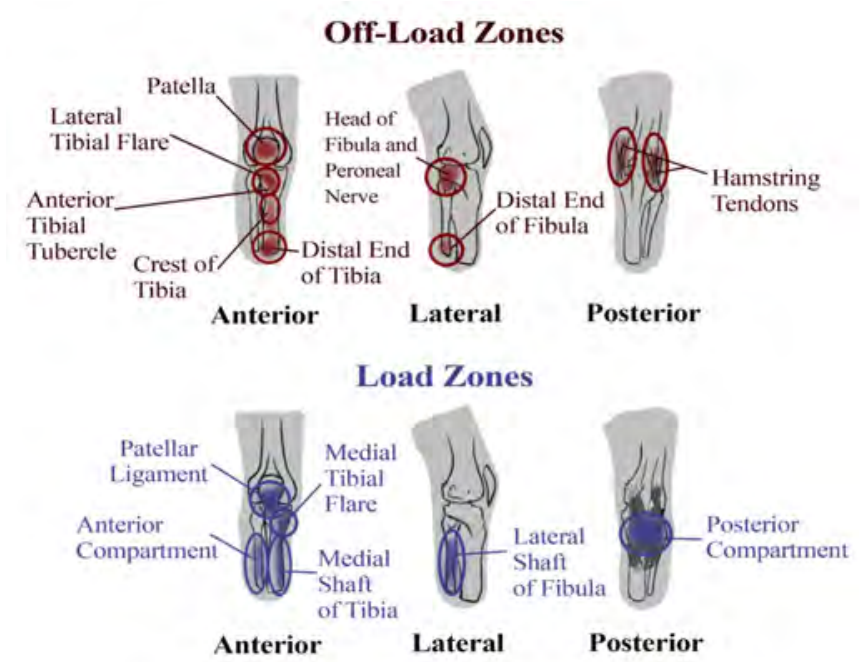

Fig. 2. Diagram outlining anatomical features and load zones that must be considered when shaping a transtibial prosthetic socket (@) 2020 Cabrera et al. [24]. Used with permission.

Both the amputation and the prosthetic manufacturing processes require multidisciplinary teamwork. Furthermore, prosthetists must meet specialized professional standards and counsel patients on recovery [21]. Prosthetist expertise influences all stages of amputee healthcare, from surgery to rehabilitation. For instance, the amputation surgery must be performed with rehabilitation in mind, or else it will not be possible for the amputee to wear a prosthetic once their limb is healed [19]. There are different types of prostheses needed for each stage of rehabilitation. Postoperative and initial protheses are provided directly after amputation. Preparatory prostheses are used for 3-6 months following amputation as a transitional device. Definitive prostheses are built once the residual limb has stabilized. They last from 3-5 years before needing replacement due to atrophy, changes in weight, or other factors [21], [22].

Due to variations in patient morphology, prosthetic manufacturing requires custom fitting the device to the body [12]. 
First, the prosthetist constructs a negative impression of the limb by fabricating a hollow cast. Then, the cast is filled with plaster to produce a positive plaster model. Using personal judgment, technical knowledge, and craftsmanship, the prosthetist models the morphology of the limb. While shaping the cast, the prosthetist anticipates the amputee's projected activities and plans the final prosthetic shape accordingly [21]. They wrap the residual limb in plaster bandages, layering more material over pressure-sensitive areas (such as bony prominences) and removing material from weight-bearing, pressure-tolerant areas (such as soft tissues) (Fig. 2). The cast is removed, filled with plastic slurry, then destroyed, leaving a solid model of the residual limb. Finally, the socket is constructed using plastic or epoxy resin-infused carbon fiber [2] (Fig. 3). After manufacturing, the socket is tested using pressure probes and adjusted accordingly. Dynamic alignment can take several hours of controlled testing. Further modifications require at least one week of physical therapy [21].

There are many disadvantages to the traditional manufacturing process. Constructing prosthetic sockets requires intensive manual labor, specialized decision-making, and multiple follow-up consultations. Unfortunately, this process must be repeated at frequent intervals to replace sockets over time [2], [25]. Current methods waste materials by destroying preliminary models. Furthermore, high quality sockets consist of expensive aerospace materials, which adds to the overall production cost [21].

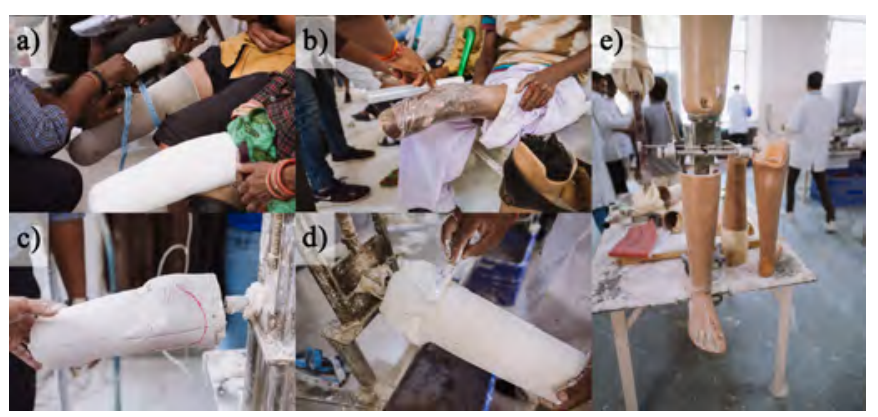

Fig. 3. Traditional process for manufacturing prosthetic limbs. a) Measuring key patient features. b) \& c) Creating a plaster cast of an amputee's limb. d) Shaping the plaster limb cast. e) Manufacturing and adjusting final prosthetic socket

\section{Prosthetic Distribution and Patient Response}

The current distribution process for prosthetics has many drawbacks. Since treatment revolves around the clinic, materials are usually ordered on a limited basis directly from independent suppliers. These small scale operations have a restricted range of services and high production costs. It is very difficult for clinics to provide the full range of services recommended by the WHO at an affordable cost using traditional methods [1]. Accessibility issues are compounded by the scarcity of clinics. Patients, especially from rural areas, bear a significant burden searching for a clinic to receive affordable care. To reduce travel time and cost for patients, the density of clinics should be increased.
Recovery does not end when a patient receives a prosthetic; amputees can experience problems due to wearing prostheses. Patients express dissatisfaction with poor fit, accessibility to repair specialists, and the high cost of treatment [5], [26]. An assessment of patellar tendon bearing sockets in Cambodia and Vietnam discovered that only 52\% of cases achieved a proper fit [27]. Ill-fitting sockets can cause blisters, neuromas, inflammation, soft tissue calcifications, pressure sores, epidermoid cysts, and other health problems [28]. Causes of prosthetic pain include excessive end bearing, uneven skin pressure, frictional skin loss, loss of total contact, hammocking phenomenon, and inlet impingement [29]. 57\% of transtibial amputees suffer from moderate to severe pain when wearing a prosthetic limb [30].

To address fit problems, prosthetics users can consult repair specialists. However, amputees report that the process of getting adjustments is inconvenient, inaccessible, and unaffordable [5], [19], [31]. Poor fit and durability can be extremely frustrating. Amputees are less willing to invest in uncomfortable prosthetics, especially if they are not able to get proper adjustments [19]. Even if good fit is achieved in a prosthetic, the lifetime of the device is limited. Temporary prosthetics must be replaced after 6-12 months, and definitive prosthetics only last 3 to 5 years [32]. There is a need for lightweight, durable, and inexpensive socket materials that can survive a complete design cycle and improve the patient experience [5].

Changes must be made to improve the quality and efficiency of prosthetic manufacturing and distribution. Digital technologies offer a promising solution to the limitations of current prosthetic design, manufacturing, and distribution.

\section{Shifting Trends Towards Virtual Care MODELS}

\section{A. Development of Digital Approaches for Prosthetic Care}

Over the past 30 years, interest has shifted towards the integration of computerized workflows into existing clinical practice for manufacturing prosthetics. Virtual technologies have the potential to increase the efficiency of prosthetic production and decrease manufacturing cost. Computer aided design (CAD) and computer aided manufacturing (CAM) technologies have been tested for prosthetics applications since the 1980's, yet implementation has been limited [33]-[35]. Walsh et al. [36] developed a digital prosthetic workflow using CAD/CAM technology, which consisted of three fundamental steps: 1) scanning the residual limb shape with a digitizer; 2) producing a virtual socket model from the scan data; 3 ) carving the socket shape from plaster or foam using a computer numerical controlled milling (CNC) machine [33]. This early process can be seen in the figure produced by Boone et al. [37] (Fig. 4). Today, virtual prosthetic workflows follow this template with three main steps: 1) limb scanning, 2) socket rectification, 3) computer aided manufacturing (Fig. 5).

\section{B. History of Computer Aided Design for Prostheses}

Early virtual workflows prioritized data collection and virtual socket design. In the 1985 special issue of Prosthetics and 


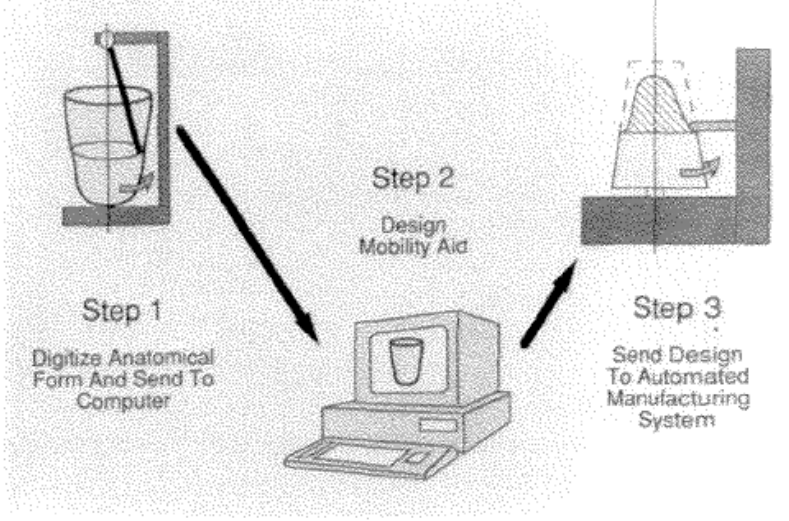

Fig. 4. Early digital workflow for designing and manufacturing prosthetic sockets (C) 1994 Boone et al. [37]. Published by JRRD. Open access, used with permission.

Orthotics International, George Murdoch noted that simulating the molding process and socket layout with CAD before fabrication would increase productivity and accessibility [34]. In this same issue, Klasson et al. [38] highlighted the benefits of CAD such as its ability to store design information, simplification of the modelling process, and efficiency of the workflow by eliminating intermediate steps. At the time, the complexity of socket models was hindered by primitive CAD software.

As CAD continued to be explored for prosthetic design, practitioners discovered that measurements of the residual limb did not need to be as precise as previously expected. The time and expense of fitting a socket could be reduced using simplified data collection methods. Private clinicians produced reasonably successful models with just a few hand measurements [34]. Though research groups have explored digital design technologies over the past forty years, improvements are needed to fully integrate virtual workflows into the clinical environment. Specifically, researchers have expressed a need for more specialized design software. Their ideal program would incorporate clinical data and prosthetic-specific tools, such as variable socket wall flexibility [33].

\section{Digital Distribution of Prosthetic Devices and Patient Response}

CAD/CAM technologies have been utilized successfully in several clinical settings. Healthcare models incorporating $\mathrm{CAD} / \mathrm{CAM}$ procedures were implemented in the Veterans Administration by Hanger Orthopedics. Their complete inhouse CAD system successfully produced prostheses within a delivery window of 24 to 48 hours using simple measurements and trained technicians. While the complexity of updating the system initially raised concerns about long term sustainability, a review of the program reported over five million dollars of savings. In the developing world, a CAD/CAM approach was implemented in 1990 by the Prosthetics Outreach Foundation in a clinic at Hanoi, Vietnam. Here, this technological approach increased accessibility to critical services at an affordable cost [34].

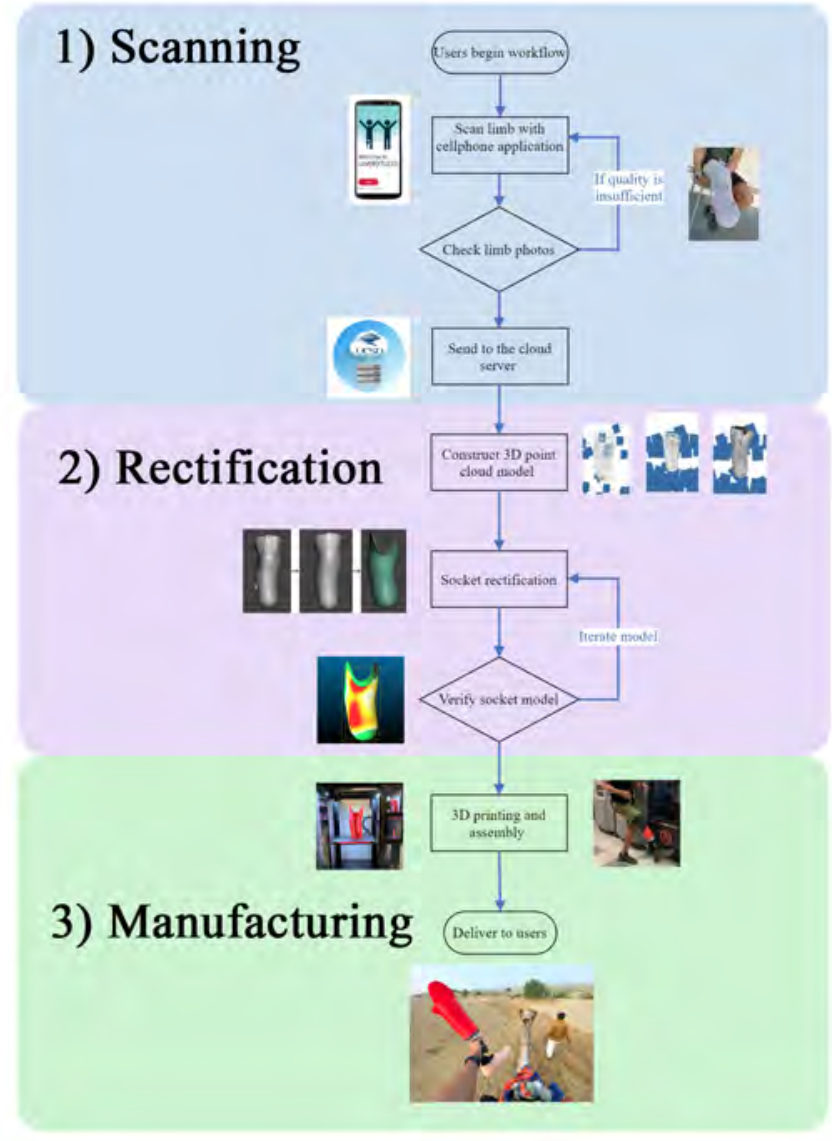

Fig. 5. Modern example of a digital workflow for designing and manufacturing prosthetic sockets (adapted from (c) 2020 Cabrera et al. [24]. Used with permission)

Based on these early successes, CAD/CAM methods are now an important part of global telemedicine initiatives. Telemedicine uses information and communication technology to provide healthcare to people living in areas with clinic shortages, or who face transportation obstacles. The Department of Rehabilitation Medicine at the Philippine General Hospital established the Amputee Screening through Cellphone Networking (ASCENT) program to provide remote care to amputees. Cell phones recorded medical history through photos and videos, which enabled user-friendly, paperless evaluations. With this digital record, the system provided screening tools for prosthesis use, created an amputee registry, and identified at-risk patients [1].

Though remote systems increase accessibility and produce useful medical data, they come with unique challenges. Entirely remote approaches can potentially result in ill-fitting and uncomfortable prosthetic sockets. In addition, it is difficult for patients to begin the necessary physical therapy using these telemedicine tools. Patients can describe their pain through a telemedicine system, but the causes may be difficult to determine without in-person consultations. Furthermore, the benefits of CAD/CAM technologies are diminished if they are not fully integrated into the telemedicine system. CAD/CAM methods have significantly shortened delivery time 
and reduced material costs in most scenarios. However, in some cases unforeseen challenges raised expenses instead of decreasing them [39], [40].

\section{Current Needs in Critical Technologies}

Both breakthroughs and challenges have shaped the history of CAD/CAM technologies in prosthetics. Today, most virtual approaches continue to adopt the fundamental three-stage workflow of data collection, virtual modelling/design, and manufacturing. Specifically, for digitally building prosthetics, these three steps can be considered as (1) 3D model acquisition; (2) model rectification into a usable geometry; (3) model manufacturing using various computer controlled approaches. Here we analyze these technologies and discuss their strengths and weaknesses.

\section{A. Technologies for 3D Model Acquisition}

To generate a 3D model of a prosthetic limb, the geometric data of the limb anatomy must be acquired [30]. After the data is collected, the scans are often processed and analysed through reverse engineering to determine the distribution of bone and skin in the limb. This anatomical information determines the final socket geometry [41].

There are many different methods to capture the geometry of a residual limb, and each method has its own set of benefits and drawbacks. 3D model acquisition methods relevant to the prosthetics field include: prosthetics specific digitizers, magnetic resonance imaging (MRI), ultrasound, laser scanning, structured light scanning, and photogrammetry (Fig. 6). There is no consensus on the best technique to form a digital model of a patient's residual limb, but an ideal method would gather data instantaneously with sufficient accuracy [42]. Other key technology considerations include cost and complexity. Though precision was also thought to be of importance for 3D modeling in the past, sockets have been successfully designed with low precision methods [34].

1) Prosthetic Specific Digitizers: Digitizers have been in widespread use for CAD modeling in the prosthetics field for several decades [34]. Prosthetic specific digitizers gather data from a cast or mold of the residual limb. A probe reads the radial coordinates of landmarks across the cast surface, which are used to create a CAD model of the limb geometry [21]. There are three major types of digitizers: mechanical, optical, and electromagnetic. Mechanical digitizers rotate around the inside of a cast or the outside of a mold. The system maintains contact while a sensor collects data on the location of the probe. Handheld electromagnetic digitizers also remain in contact with the surface being captured, but their motion is recorded relative to a specific electric field. Finally, optical digitizers project laser light onto a mold, then a digital camera records the geometrical curvature. Though optical digitizers are sufficiently accurate for most clinical applications, increasing the accuracy of readings could lead to improvements in socket fit [45].

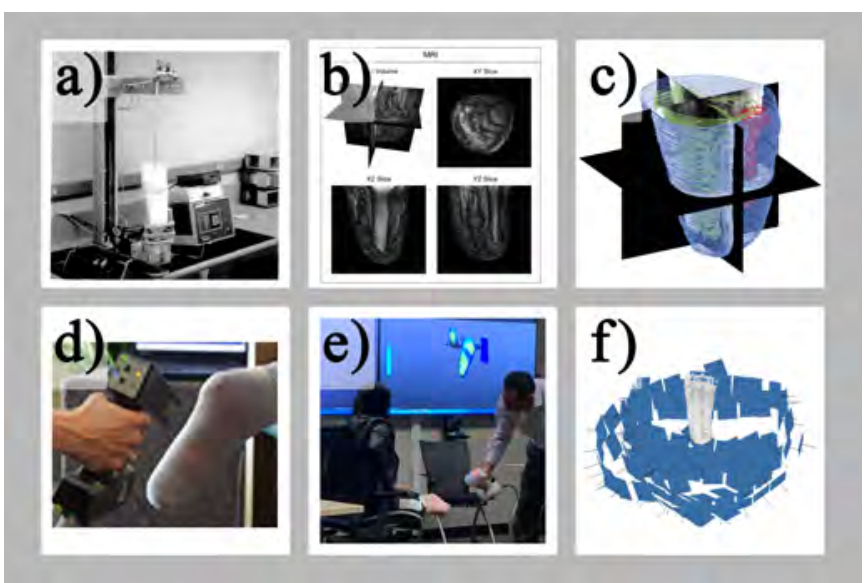

Fig. 6. This figure portrays several different methods that are used to digitize residual limb geometry. a) Manual Digitizer ( 1994 Boone et al. [37]. Published by JRRD. Open access, used with permission. b) Magnetic Resonance Imaging (MRI) () 2019 IEEE. Reprinted, with permission from Ranger et al. [43]. c) Ultrasound (c) 2019 IEEE. Reprinted, with permission from Ranger et al. [43]. d) Laser Scanning (C) 2014 Polhemus [44], used with permission. e) Structured Light f) Photogrammetry

2) Magnetic Resonance Imaging (MRI) and Computed Tomography (CT): Magnetic Resonance Imaging (MRI) and Computed Tomography (CT) have been implemented extensively throughout the medical field. These imaging technologies benefit prosthetic design because they capture both internal and external features of residual limbs [46]. Visualizing the relative positions of bones and soft tissues can help clinicians predict the pressure distribution on a residual limb. They can then use this information to tailor the socket design for each patient, including the desired mechanical properties of the socket wall [15], [46], [47]. Both procedures require the patient to remain still (to minimize deformation) while they collect images at incremental distances across the limb. A 3D model is generated by stitching together the cross sectional data for each surface area into a point cloud [48].

MRI is a noninvasive scanning method that uses Nuclear Magnetic Resonance (NMR) to map the distribution of hydrogen atoms in the body. The MRI machine creates a magnetic field to orient the hydrogen atoms, then applies radio waves to alter the atom positions. A sensor detects the spin of the atoms realigning to the magnetic field after the waves dissipate, then the data is processed to produce a 3D image [49].

MRI is useful for prosthetics applications because this method displays the distribution of bones and soft tissue, which can be analysed to determine pressure-sensitive and pressure-tolerant areas [50]. MRI is less invasive than other common scanning methods such as CT, since MRI does not expose patients to harmful radiation [51], [52]. However, MRI poses significant disadvantages in the context of the amputee problem. It is more expensive than other methods, plus medical implants and metal shrapnel can interfere with the imaging process [30].

Compared to MRI, which excels at imaging soft tissues, CT is more useful for capturing bony anatomy [48]. Cross sectional images captured by CT distinguish between bones and 
skin using different gray level values, which preserves internal and external limb anatomy information [15]. Researchers at the University of Texas at Austin used CT scan data to obtain the shape of the residual limb, bones, and tissues. They constructed a detailed CAD surface model and used the scan data to determine the geometry of the inner socket wall [52]. One disadvantage of $\mathrm{CT}$ is that it exposes patients to ionizing radiation, similar to X-ray imaging [30], [48], [52]. Given this limitation, CT is not an ideal scanning method.

3) Ultrasound Imaging: Ultrasound is one of the most unique technologies used to generate limb models. Ultrasound imaging begins with the application of a gel to the surface of interest. A probe remains in contact with the skin, and collects images that are stitched into a volume. Ultrasound uses piezoelectric transducers to generate acoustic waves; these waves travel through the human body and become scattered by different tissues. A 2D image of the internal geometry can be generated by capturing the reflected acoustic waves using a transducer array. These $2 \mathrm{D}$ images can be stitched together to form a 3D model [53].

Ultrasound imaging is a relatively simple, portable, and cost-effective scanning method. This procedure is less invasive than CT and faster than MRI. As a safe, instantaneous, adequately accurate method of data collection that requires minimal training, ultrasound has many favorable characteristics that could streamline the scanning process. These benefits inspired prosthetic researchers to try to reconstruct residual limb geometries using ultrasound [30], [43], [53].

However, one potential problem that can occur with imaging is that the contact between the probe and the residual limb surface can deform soft tissues. This pressure causes limb motion and can result in an inaccurate 3D model. Placing the transducer between the limb and the socket can create a coupling problem and decrease image quality [53]. Different setups, such as a water bath, have been explored to improve the accuracy of ultrasound imaging. Ideal scanning procedures would minimize preparation to save time for the patient and practitioner [30], [43].

4) Laser Scanning: Laser scanning projects a pattern of light onto a subject, which could be a single point, single line, or multiple lines arranged in an array. The laser is produced from a single beam of light using an optical system of mirrors, then acquired using a camera sensor. The angle of reflection is calculated to determine the locations of various landmarks on the surface in a process called triangulation. Due to interferences between light sources, laser scanning can require a longer time than other methods to capture limb geometry [42], [54]. However, this method provides high resolution images that preserve more details than other scanning technologies [16].

The FastSCAN system utilized by Sengeh et al., [46] is a successful implementation of the laser scanning method for prosthetics and orthotics. This tool can display a 3D model as it is rendered in real time. Additionally, the Hanger Orthopedic Group has developed clinical protocols with their INSIGNIA laser scanning system [55].

5) Structured Light: Structured light scanning is a noninvasive, fast, and accurate method for acquiring 3D models.
Easily operated using a handheld scanner, the procedure begins when a projector casts light patterns (also known as fringe patterns) onto the surface of interest. A camera array records the distorted light pattern, then the 3D geometry is determined by calculating the differences between points in the captured images (through pattern fringe triangulation) [54], [56]. The image of the surface is collected without the pattern to gather textural information. Finally, the geometric and textural data are combined to form a 3D model of the residual limb.

Structured light scanning has been used for a variety of biomedical applications due to its ability to model skin surfaces. A high-resolution 3D model of a mid-sized object can be acquired in 1-2 minutes through the handheld structured light scanning process [56]. Structured light has been used by WillowWood, Autodesk, NiaFit, and researchers at the University of Toronto to create 3D models for prosthetics [57][59]. The main limitation of the structured light technique is that high-resolution equipment can be costly. Structured light scanners, while generally robust, can be affected by local reflectivity and geometric configurations, resulting in distorted models [60].

6) Photogrammetry: Photogrammetry assembles 3D models based on 2D images taken from different viewpoints relative to the surface of interest [61]. Using interior, relative, and absolute orientations, the geometry of the original photos is duplicated, then the relative positions between photos are recreated. The images are transformed into a 3D point cloud based on their epipolar geometrical configuration. Finally, this point cloud can be synthesized into a 3D model using mesh building techniques [62].

Metric photogrammetry provides precise geometric information, while interpretive photogrammetry focuses on object recognition. The image can be captured simultaneously by multiple cameras in different positions (stereophotogrammetry) or by one camera that takes images sequentially from different positions (monoscopic photogrammetry) [63]. In the prosthetics field, photogrammetry has been used for facial prostheses and modeling the interior of prosthetic sockets [64], [65]. Recently photogrammetry has been used to scan amputees' residual limbs for making transtibial prosthetic sockets [24], [66]

Though it is slightly less accurate and requires more effort than scanning methods such as structured light and MRI, a key benefit of photogrammetry is that the procedure can be accomplished at a lower cost using readily available technology [64]. Specifically, photogrammetry can be executed using a smartphone camera and cloud-based software, which makes this scanning method readily accessible [24], [65]. Using normal smartphone cameras, the photogrammetry technique is capable of sub-millimeter accuracy and precision [67].

Photogrammetry costs about ten times less than laser or structured light scanning methods [54]. This noninvasive method collects sufficiently accurate data that can be saved for offline use if adjustments need to be made later in the workflow [42]. Data acquired through photogrammetry has produced 3D anatomical models that can be transformed into a prosthetic with CAD manipulation [65]. However, the scanning process requires several conditions be met or else reconstruction 
can fail. The ideal scanning environment includes a stable reference, a patterned surface, and consistent lighting [64], [65], [68].

\section{B. Technologies for 3D Model Rectification}

Once the limb geometry has been captured, this model must be modified into a prosthetic socket that a patient can wear. This stage is known as rectification. This design stage typically requires a prosthetist with several years of experience shaping sockets. Simulating the traditional rectification process in a digital environment is one of the most important steps towards enabling a virtual care model. A whole host of different software platforms have been developed to enable clinicians to shape prosthetic sockets digitally (Fig. 77). One of the main challenges of the rectification stage is the lack of quantitative guidelines to help practitioners shape prostheses in an automated fashion.

Despite more than 30 years of commercial and university development, inadequate software tools for rectification provide the largest hurdle for virtual prosthetic socket design. Many of the problems stem from the more gradual pace of computer aided design (CAD) software, but a larger obstacle has been the lack of technologies to take clinical information into account for a quantitative design model. Current rectification technologies attempt to institutionalize tactile prosthetist knowledge, but fail to take advantage of more advanced computing methods for automation and machine learning.

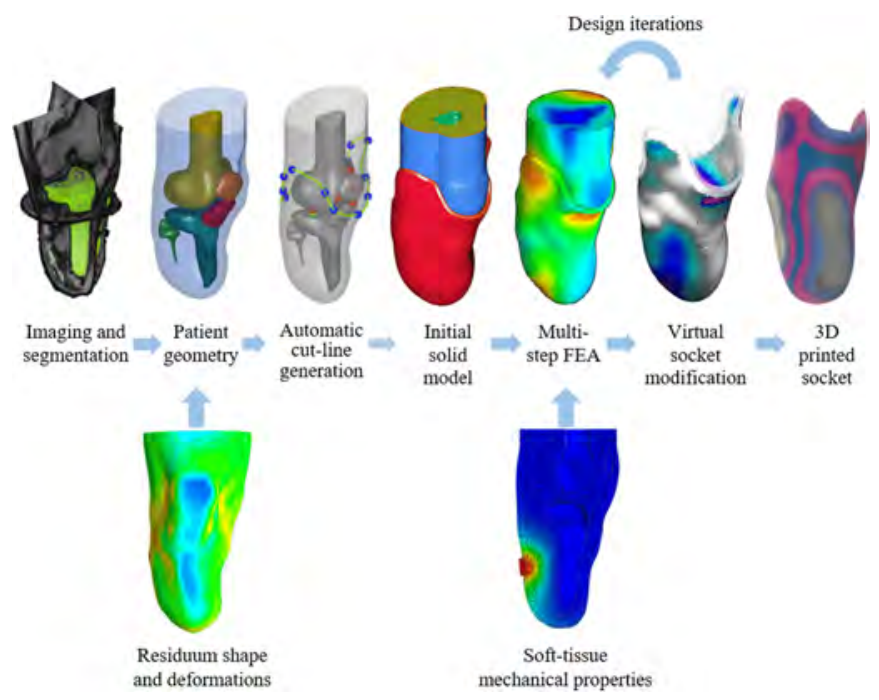

Fig. 7. Example of a digital limb model being rectified into a 3D printed socket (C) 2019 IEEE. Reprinted, with permission from Solav et al. [69].

1) Research Software: One of the earliest socket rectification software, ShapeMaker, developed as a result of the VA's Automated Fabrication of Mobility Aids (AFMA) effort [37]. This pioneering software built in a great deal of useful functions, such as templates for different types of prostheses and pinpoint shape modification based on anatomical features. This software also incorporated an early version of a fully automated design feature, though it was quite limited.

A much more advanced successor to ShapeMaker, the socket modeling assistant (SMA) is a semiautomated socket rectification method developed by Colombo et al. [70] and Buzzi et al. [71]. This software implements several key advances, including the ability to import clinical parameters when facilitating socket rectification. Some of these parameters include: tonicity, skin condition, height, weight, and activity level. As an additional benefit, socket fit can be tested within the software package through a built-in finite element analysis (FEA) tool. However, SMA requires a high quality residual limb model typically generated from CT or MRI scans, which can be expensive and difficult to obtain.

The most advanced research in digital socket rectification utilizes genetic algorithms and eigenvector algorithmic methods to create nearly fully automated shaping approaches [72][74]. These new techniques utilize automation advances in the field of computer science to rectify sockets. They are much more intelligent than purely programmatic rectification. Despite being far from commercial implementation, these algorithms are the most likely methods to bridge the gap towards creating an automated rectification system.

2) Commercial Solutions: OMEGA is a commercial CAD software package developed by WillowWood that is widely used in prosthetic clinics. This software includes "tools for shape capture, design and fabrication," such as shape alignment, landmark identification, and a goniometer tool for measuring and changing angles [58]. Residual limb models can be imported into the OMEGA software through additional hardware tools offered by WillowWood. In some cases, a model can be generated just from physical measurements of a patient. One drawback is that this software requires a high level of expertise to be used to its maximum potential.

NiaFit is a promising socket rectification software built on the Autodesk Meshmixer platform and developed by the nonprofit Nia Technologies. This software can use the advanced .STL shaping tools of Meshmixer. NiaFit enhances the functionality of digital socket rectification by creating a simplified workflow and enabling the shaping of sockets in virtual reality (VR) [59]. Unfortunately, this software is currently under private development and is not available for widespread testing and use.

\section{Technologies for Additive Manufacturing of Prosthetic Models}

Additive manufacturing (AM) is the most commonly used CAM technology for bringing digital prosthetic socket models into reality. Rather than subtracting from an existing block (like in CNC milling) AM builds structurally complex objects by depositing material layer by layer [21], [75], [76]. AM technology has been used since the 1980s for medical devices, implants, and even building human tissues [76], [77]. Examples of AM include fused deposition modeling (FDM), selective laser sintering (SLS), and stereolithography (SLA) (Fig. 8).

AM has several advantages over traditional methods for fabricating prosthetic sockets. One drawback of the traditional method is that the cast is destroyed, providing no permanent record of anatomical geometry [16]. The AM process preserves this geometry in a digital format, which allows for 
simple design adjustments and the ability to create several reproductions of the same model [16], [78]. AM uses fewer materials, requires less patient participation, and takes less time to create a final prosthetic geometry than traditional methods [16]. Another strength of AM is that this method has extraordinary flexibility when it comes to material choice. Plastics, metals, ceramics, biomaterials, and composites can all be fabricated with AM [47]. Furthermore, AM can tailor specific mechanical properties across the socket [34].

A key obstacle to the integration of this technology in the prosthetic field has been limitations in the strength of AM materials. Other challenges include the cost and uncertainty of investments into 3D printing, particularly due to rapid advancements in technology [1], [34], [78]. However, if these hurdles can be overcome, then AM technology can significantly increase access to affordable prostheses [1].

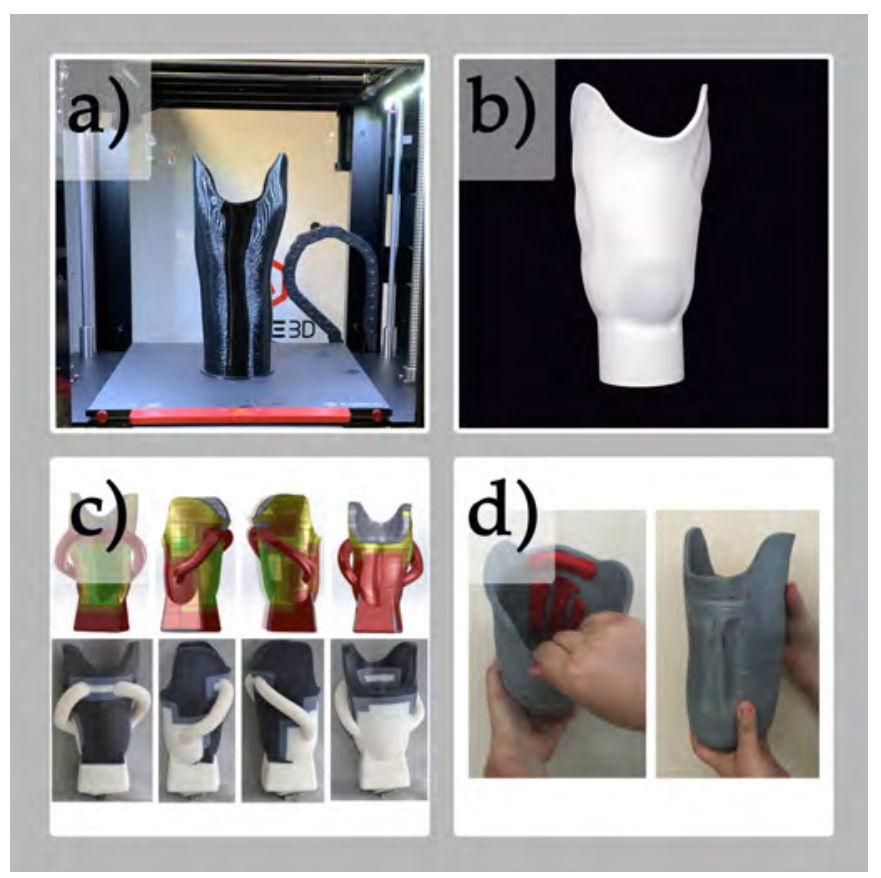

Fig. 8. Examples of prosthetic sockets manufactured with different AM technologies: a) FDM b) SLS (C 2007 Rogers et al. [33]. Reprinted by Permission of SAGE Publications, Ltd. c) Inkjet (C) 2013 Wolters Kluwer Health, Inc. Reprinted with permission from Sengeh and Herr [46]. d) Multi-material printing (C) 2015 Comotti et al [47]. Reprinted with permission from Association for Computing Machinery.

1) Fused Deposition Melting (FDM): Fused deposition melting (FDM) has many applications in prosthetic engineering [79]. FDM is the most commonly used AM technology for prosthetic socket manufacturing due to availability and low cost. This technology can quickly manufacture large models with relatively high accuracy. In FDM, materials such as acrylonitrile butadiene styrene (ABS) and polylactic acid (PLA) are heated, forced through a printer head, then extruded in layers onto a print bed. While FDM is capable of building structures with challenging geometries, there are certain restrictions. Components must be supported with physical material since there are limits on the size of unsupported overhangs [79].

Sockets have been successfully produced using FDM, but past researchers noted that these structures were not strong for implementation [78], [80]-[83]. A unique approach to FDM, the Squirt Shape system was developed at Northwestern University in 1992. Squirt Shape was used to construct a socket with single-layer walls of uniform thickness [34], [84], [85]. In 1998, Lee et al. [86] constructed two FDM sockets that demonstrated minimal variations in gait compared to conventional prosthetic sockets [87]. FDM was used by Hsu et al. [78] to construct a resin-reinforced polycarbonate socket in 2010. Among commercial prosthetics applications, FDM has been used in Nia Technologies' 3D PrintAbility system [59].

2) Selective Laser Sintering (SLS): Selective Laser Sintering (SLS) is a type of AM that uses a laser beam to coalesce powder particles together in selected cross sectional areas. The sintered cross sections are then fused to create a 3D object [77]. SLS can construct complex geometries from many materials, and has been investigated for prosthetic socket manufacturing for decades. Sockets manufactured with SLS were noted to have a quick production time, though problems arose with material strength [87]. Faustini et al [52] fabricated an SLS socket from Duraform PA using a Sinterstation 3500. The researchers noted that the 15 hour, $\$ 527$ process facilitated the integration of other prosthetic components, such as a pylon mounting system, with a tolerance of $0.25 \mathrm{~mm}$. Rogers et al. [33] produced an SLS socket comparable to conventional sockets, however the sintered material eventually broke under loading. While SLS has been explored for flexible-wall socket designs, high cost and complexity have been barriers to successful fabrication [33], [87], [88].

3) Stereolithography (SLA) and Inkjet Printing: Stereolithography (SLA) constructs objects using a near UV laser beam. The laser beam draws a cross section onto liquid photopolymer resin, which polymerizes in response to the radiation. The hardened cross sections are layered to build a 3D structure [77]. Working with Baxter Healthcare in 1990, Northwestern University made a transtibial socket using SLA [85], [87].

Inkjet printing is an AM process that deposits solvent droplets onto a substrate. Inkjet printing is a highly accurate method that generates very little waste because material is added only where specified. [89]. Sengeh et al. [46] printed a variable impedance socket on an Objet printer (inkjet). One benefit of this technology was that it was capable of multimaterial printing. The researchers built a prosthetic socket with different compliances by locally controlling the material properties during the printing process. However, long term durability was not demonstrated, and preliminary data suggested a lower factor of safety. Since a large wall thickness was required for structural integrity, the variable impedance socket was almost 3 times heavier than a conventional socket.

4) Multi-Material Printing: Recent research has attempted to integrate multiple materials into a single FDM print to create sockets with distinct stiff and compliant regions [47], [77]. Multi-material 3D printing takes advantage of the large range of AM materials as well as the different infill densities and patterns that impact the overall socket structure. Additionally, multi-material printing can improve the ease of manufacturing by allowing the use of water soluble supports that are easily removed after printing. 
In 2015, Comotti et al. [47] constructed a prosthetic socket with heterogeneous material composition using the "Leonardo 300 Cube" printer by Meccatronicore. Locally manipulating material hardness based on the distribution of pressure zones increased comfort, decreased material fatigue, and increased overall socket strength. Rubber materials allowed for large deformations in off-load areas, while harder materials such as PLA provided mechanical resistance in load areas. While multi-material printing demonstrates potential for the customization needs of prosthetic sockets, more research must be done to validate strength and durability.

\section{Technologies for Analyzing Patient Response to Wearing Prostheses}

All prosthetists seek to quantifiably understand how their patients respond to different prosthetic socket designs. This is true regardless of whether the prostheses are manufactured using digital tools or traditional methods. Qualitative clinical outcomes from ill fitting prosthetic sockets are fairly well understood. However, technologies that can precisely identify problematic design practices and give specific feedback to clinicians are invaluable. These technologies have seen rapid development in the past few years and encompass both experimental techniques and completely virtual simulations (Fig. 9).

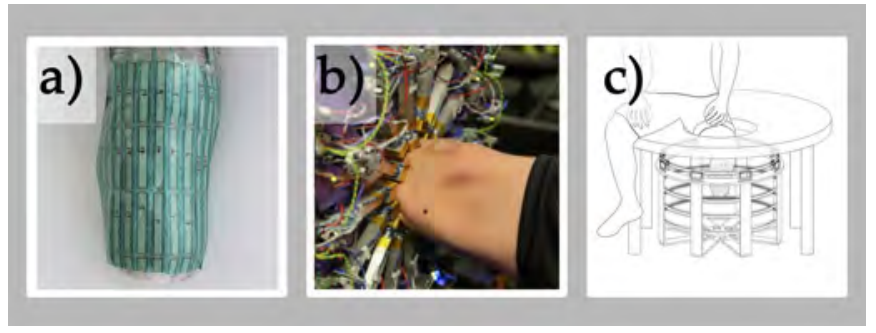

Fig. 9. Examples of tools utilized for quantitatively analyzing patient response: a) Transducer array (c) 2013 Ali et al. [90]. Published by Elsevier Ltd. Open access, used with permission. b) Fitsocket. Reprinted from Sengeh et al. [50]. (C) 2016 Elsevier Ltd., used with permission. c) Digital Image Correlation (DIC) (C 2019 IEEE. Reprinted, with permission from Solav et al. [69].

1) Experimental Technologies to Quantify Patient Response: The distribution of interface stresses affects load transfer between the residual limb and the prosthetic socket, which impacts overall comfort [91]. For instance, increased stresses on the skin interface can cause pain, skin problems, deep tissue injury, and musculoskeletal problems [69], [92], [93]. Force transducers quantitatively measure interface stresses and can be placed on the surface of the socket wall or embedded within the socket wall. These transducers measure either the residual limb/liner interfacial stress or the liner/socket interfacial stress [91], [94].

Types of force transducers include: piezoresistive, capacitive, strain gauges, and optical sensors. Piezoresistive transducers are thin, flexible structures with good sensitivity to pressure. Critically, they cannot quantify shear stresses. Capacitive transducers, strain gauges, and opto-electronic systems can measure both normal and shear stresses. However, strain gauges are limited to isolated sites, capacitive transducers are sensitive to noise, and opto-electronic systems are susceptible to fiber damage [91], [95]. Using a mapping function between pressures and related strains, Artificial Neural Networks (ANNs) rapidly predict pressure distributions without interference. Still, more research is needed for validation [95].

The FitSocket System is a novel, noninvasive method for determining residual limb tissue properties developed by Sengeh et al. [50]. FitSocket combines MRI with inverse finite element analysis (FEA) to capture the detailed anatomy of the limb. To gather data, a residual limb is inserted into the FitSocket device, then the device is manually rotated and translated around the limb. MRI gathers the geometric data of the limb's surface and internal structures. Then, multiple in-vivo indentation tests (conducted at different points on the limb) characterize tissue mechanical behavior. The indentors gather force versus time data at each site to establish boundary conditions for the inverse FEA optimization process. The optimization interpolates the difference between numerical and experimental data to create the model. The FitSocket preserves key details for evaluating the complex effects of various loading conditions on the limb. Anatomical features such as skin surfaces, tissue boundaries, and bones are represented with varying geometric and mechanical characteristics across the FEA model. However, experimental design limitations caused many sources of error, which complicated the optimization process. As a result, developing the 3D model was slow; it took between 10-60 minutes for the simulation to converge and the results to be imported for analysis.

Unlike force transducers, digital image correlation (DIC) is a non-contact method that can be used to measure limb deformation [96]. DIC is a useful tool for calculating limb volume changes that lead to limb-socket interface stresses. Using a multi camera array and the MultiDIC toolbox developed by [97], Solav et al. [69] measured time-varying shape fluctuations, volume changes, deformation, and strain upon socket removal.

Another quantitative clinical indicator of patient comfort is pistoning, which is the vertical movement of the residual limb inside the socket. Gholizadeh et al. [98] used a photographic method to quickly measure socket/liner pistoning in full weight bearing, non-weight bearing, and static axial loading conditions. Though many methods are available for quantitatively measuring patient response, many researchers have expressed interest in predictive models to streamline the socket design process.

2) Simulations to Predict Patient Response: There are many situations where it is necessary to simulate a patient's response using numerical computational methods. Finite element analysis (FEA) is the most common method for virtually predicting patient response [99]-[106]. This discrete numerical modeling method allows engineers to gain insights that are not possible with current experimental technologies. Dickinson et al. [99] outlines many benefits of FEA for analyzing patient response. FEA can offer novel insights into internal soft tissue mechanics and residuum-prosthesis interfacial stresses. It can also be used to reverse engineer residual limb tissue properties. These insights allow researchers to identify potential risk factors, test 
out new prosthetic concepts, and improve current prosthetic design technologies.

However, these FEA methods have certain limitations that inhibit them from being used on a widespread scale. Notably, the high modeling complexity consumes vast computational resources, while yielding only specific results. A single simulation cannot be generalized easily since patient limbs and prosthetic designs vary tremendously. In addition, many comfort and pain thresholds are subjective because the mechanisms for tissue adaptation are not well understood. FEA simulations rarely consider full dynamic loading conditions, which are more realistic than static loading conditions [99], [107]. These factors currently limit the implementation of FEA into clinical use. However, creating automated versions of these computational tools would enable clinicians to utilize the unique benefits of FEA.

\section{CONCLUSIONS}

Amputation is a major global issue. Around the world, at least 35 million amputees currently do not have access to prosthetic healthcare. This negatively impacts their ability to work, learn, and carry on with a normal life. In turn, they face discrimination, which only compounds their struggle. A prosthetic limb can change an amputee's life for the better. Current clinical methods for designing and building prosthetics are quite successful in improving patient outcomes. This is especially true in developed nations such as the United States and Europe. However, traditional methods are so laborintensive that they can never be scaled up to match the extent of this global problem. The vast majority of amputees live in developing nations, with healthcare systems that cannot meet their needs. Digital technologies will transform the face of prosthetic healthcare because they can address these accessibility issues on a broad scale.

Overall, the shift in prosthetic care towards utilizing digital tools has been a slow process. However, after 30 years of research, improvements in digital CAD/CAM technologies are showing signs of success for prosthetic applications. These technologies can build affordable prosthetics faster and on a larger scale than previously possible. Digital tools for designing and manufacturing prosthetic sockets are built on three fundamental pillars: limb scanning, socket rectification, and computer aided manufacturing. These digital healthcare technologies reduce the need for in-person patient participation, create records of valuable clinical data, and open the door for remote prosthetic production. Telemedicine healthcare models have demonstrated success and could be integrated with digital prosthetic workflows to increase clinician impact. However, the need for expertise and in-person consultations remains critical to care, and the current state of digital technology must be improved before implementing these workflows.

Any method used to scan a residual limb's geometry must be noninvasive, sufficiently accurate, accessible and cost effective. In the clinical realm, laser scanning, MRI, and CT have been explored as tools to gather residual limb geometry. Though these methods are successful and well-established in medical applications, there remains a significant cost barrier that must be overcome to feasibly use them on a large scale. Emergent technologies such as photogrammetry have the potential to reduce this financial hurdle.

While CAD technology has advanced significantly for general 3D modelling purposes, prosthetic applications have specialized needs, which pose obstacles for most CAD programs. CAD programs need to incorporate clinical information and prosthetist guidelines to enable successful rectification of prosthetic sockets. Automated rectification tools have been explored to various degrees in the past. However, new intelligent computational methods are finally providing the ability to rectify custom sockets in a truly automatic fashion.

Additive manufacturing has been a true breakthrough CAM technology for bringing digital prosthetic models into reality. Prosthetic sockets have been built using almost every type of additive manufacturing: FDM, SLS, inkjet, SLA, multimaterial. FDM is by far the most common and cost effective method. Unfortunately, the materials used in FDM 3D printing are not currently strong enough to meet ISO safety requirements. New filament materials with sufficient strength, durability, and cost-effectiveness must be developed to address this issue.

Technologies to quantifiably analyze patient response have undergone an incredible degree of advancement in recent decades. Force transducers, photographic pistoning, DIC, FEA and other methods are allowing researchers to better understand the interfacial stresses at play within prostheses. In the future, these tools will allow for enhanced patient specific design.

Virtual workflows for designing and manufacturing prosthetics will continue to play a greater role in clinical practice as our world becomes more and more digital. These technologies will enable a single prosthetist to help more amputees, without regards to their geographical location. Creating prosthetic limbs remotely will allow prosthetists to help amputees in rural areas of developing nations that currently cannot support the infrastructure to build prosthetics locally.

Giving an amputee a prosthetic limb can transform their life and enable them to rejoin society. Millions of amputees globally still do not have any access to rehabilitative care, but digital technologies to design and manufacture prosthetic limbs will be key to bridging the accessibility gap. Digital workflows have the potential to increase the efficiency, accessibility, and quality of prosthetic care. It is critical that we all do our part to build new healthcare technologies that are innovative, effective, and affordable for all.

\section{ACKNOWLEDGMENT}

Funding for this research was provided by the Benbough Foundation, Alfred P. Sloan Foundation, UC San Diego Graduate Division, UCSD Center for Human Frontiers, and the Qualcomm Institute at UCSD. The authors also wish to thank Bhagwan Mahaveer Viklang Sahayata Samiti (Jaipur Foot) for allowing the authors to document and study their prosthetic manufacturing technology. Finally, the authors would like to thank the students involved on the Project Lim(b)itless team for their incredible energy, support, and positivity on this research journey. 
[1] Standards for prosthetics and orthotics. Organization, 2017, 2 OCLC: 1028590269.

Geneva: World Health

2] Y.-a. Jin, J. Plott, R. Chen, J. Wensman, and A. Shih, "Additive Manufacturing of Custom Orthoses and Prostheses - A Review," Procedia CIRP, vol. 36, pp. 199-204, 2015, 1. [Online]. Available: https://linkinghub.elsevier.com/retrieve/pii/S2212827115004370

[3] M. Marino, S. Pattni, M. Greenberg, A. Miller, E. Hocker, S. Ritter, and K. Mehta, "Access to prosthetic devices in developing countries: Pathways and challenges," in 2015 IEEE Global Humanitarian Technology Conference (GHTC), Oct. 2015, pp. 45-51, journal Abbreviation: 2015 IEEE Global Humanitarian Technology Conference (GHTC)

[4] A. Esquenazi, "Amputation rehabilitation and prosthetic restoration From surgery to community reintegration," Disability and Rehabilitation, vol. 26, no. 14-15, pp. 831-836, Jul. 2004. [Online]. Available: http://www.tandfonline.com/doi/full/10.1080/09638280410001708850

[5] E. Andregård and L. Magnusson, "Experiences of attitudes in Sierra Leone from the perspective of people with poliomyelitis and amputations using orthotics and prosthetics," Disability and Rehabilitation, vol. 39, no. 26, pp. 2619-2625, Dec. 2017. [Online]. Available: https://www.tandfonline.com/doi/full/10. 1080/09638288.2016.1236409

[6] Douglas G. Smith, Ernest M. Burgess, and Joseph H. Zettl, "Chapter 24A - Special Considerations: Fitting and Training the Bilateral Lower-Limb Amputee," in Atlas of amputations and limb deficiencies: surgical, prosthetic, and rehabilitation principles, 3rd ed., American Academy of Orthopaedic Surgeons, Ed. Rosemont, IL: American Academy of Orthopaedic Surgeons, 2004

[7] C. S. Harkins, A. McGarry, and A. Buis, "Provision of prosthetic and orthotic services in low-income countries: A review of the literature," Prosthetics and Orthotics International, vol. 37, no. 5, pp. 353-361, Oct. 2013. [Online]. Available: http://journals.sagepub.com/ doi/10.1177/0309364612470963

[8] K. Ziegler-Graham, E. J. MacKenzie, P. L. Ephraim, T. G. Travison, and R. Brookmeyer, "Estimating the Prevalence of Limb Loss in the United States: 2005 to 2050," Archives of Physical Medicine and Rehabilitation, vol. 89, no. 3, pp. 422-429, Mar. 2008. [Online]. Available: https://linkinghub.elsevier.com/retrieve/pii/ S0003999307017480

[9] A. M. Grabowski and S. D'Andrea, "Effects of a powered ankle-foot prosthesis on kinetic loading of the unaffected leg during levelground walking," Journal of NeuroEngineering and Rehabilitation, vol. 10, no. 1, p. 49, 2013. [Online]. Available: http://jneuroengrehab. biomedcentral.com/articles/10.1186/1743-0003-10-49

[10] D. K. Blough, S. Hubbard, L. V. McFarland, D. G. Smith, J. M. Gambel, and G. E. Reiber, "Prosthetic cost projections for servicemembers with major limb loss from Vietnam and OIF/OEF," Journal of Rehabilitation Research and Development, vol. 47, no. 4, pp. 387402, 2010.

[11] G. McGimpsey and T. Bradford, "Limb Prosthetic Services and Devices - Critical Unmet Need: Market Analysis," National Institute of Standards and Technology, Tech. Rep., 2017. [Online]. Available: https://www.nist.gov/system/files/documents/2017/ 04/28/239_limb_prosthetics_services_devices.pdf

[12] R. LeMoyne, Advances for prosthetic technology: from historical perspective to current status to future application. Tokyo: Springer, 2016, oCLC: ocn919107169.

[13] R. M. Coupland, Assistance for victims of anti-personnel mines: Needs, constraints and strategy. Geneva: International Committee of the Red Cross, 1997. [Online]. Available: http: //www.icrc.org/icrceng.nsf/c1256212004ce24e4125621200524882/ dafee8f89b11b10d412564eb002a62bd?OpenDocument

[14] "Jaipur Foot Knee/Limb," 2016. [Online]. Available: www.jaipurfoot. org

[15] Z. Shuxian, Z. Wanhua, and L. Bingheng, "3D reconstruction of the structure of a residual limb for customising the design of a prosthetic socket," Medical Engineering \& Physics, vol. 27, no. 1, pp. 67-74, Jan. 2005. [Online]. Available: https://linkinghub.elsevier.com/retrieve/ pii/S1350453304001481

[16] C. Nayak, "Customised prosthetic socket fabrication using 3D scanning and printing," Bangalore, Sep. 2014. [Online]. Available: https://www.researchgate.net/publication/274386505_Customised_ prosthetic_socket_fabrication_using_3D_scanning_and_printing

[17] M. R. Safari and M. R. Meier, "Systematic review of effects of current transtibial prosthetic socket designs-Part 2: Quantitative outcomes," Journal of Rehabilitation Research and Development, vol. 52, no. 5, pp. 509-526, 2015. [Online]. Available: http://www.rehab.research.va. gov/jour/2015/525/pdf/JRRD-2014-08-0184.pdf

[18] - "Systematic review of effects of current transtibial prosthetic socket designs-Part 1: Qualitative outcomes," Journal of Rehabilitation Research and Development, vol. 52, no. 5, pp. 491-508, 2015. [Online]. Available: http://www.rehab.research.va.gov/ jour/2015/525/pdf/JRRD-2014-08-0183.pdf

[19] J. Griffet, "Amputation and prosthesis fitting in paediatric patients," Orthopaedics \& Traumatology: Surgery \& Research, vol. 102, no. 1, pp. S161-S175, Feb. 2016. [Online]. Available: https: //linkinghub.elsevier.com/retrieve/pii/S1877056815003138

[20] D. A. Boone, T. Kobayashi, T. G. . Chou, A. K. Arabian, K. L. Coleman, M. S. Orendurff, and M. Zhang, "Perception of socket alignment perturbations in amputees with transtibial prostheses," The Journal of Rehabilitation Research and Development, vol. 49, no. 6, p. 843, 2012. [Online]. Available: http://www.rehab.research.va.gov/ jour/2012/496/pdf/boone496.pdf

[21] M. J. Quigley, "Chapter 4 - Prosthetic Management: Overview, Methods, and Materials," in Atlas of amputations and limb deficiencies: surgical, prosthetic, and rehabilitation principles, 3rd ed., American Academy of Orthopaedic Surgeons, Ed. Rosemont, IL: American Academy of Orthopaedic Surgeons, 2004.

[22] Susan Kapp and Donald Cummings, "Chapter 18B - Transtibial Amputation: Prosthetic Management," in Atlas of amputations and limb deficiencies: surgical, prosthetic, and rehabilitation principles, 3rd ed., American Academy of Orthopaedic Surgeons, Ed. Rosemont, IL: American Academy of Orthopaedic Surgeons, 2004.

[23] N. Mohd Hawari, M. Jawaid, P. Md Tahir, and R. A. Azmeer, "Case study: survey of patient satisfaction with prosthesis quality and design among below-knee prosthetic leg socket users," Disability and Rehabilitation: Assistive Technology, vol. 12, no. 8, pp. 868-874, Nov. 2017. [Online]. Available: https://www.tandfonline.com/doi/full/ 10.1080/17483107.2016.1269209

[24] I. A. Cabrera, Z. Zheng, P. Castillo, E. Ngo, S. Troncoso, W.-Y. Zhao, N. Sheth, C. Gean, J. Hsiao, J. V. Laxa, J. Martin, M. A. Meyers, J. M. McKittrick, R. R. Rao, and A. Y. Lin, "Smartphone Telemedicine: A Novel Workflow for Creating Prosthetic Sockets Using Semi-automated Photogrammetry," preprint, Jul. 2020. [Online]. Available: https://www.techrxiv.org/articles/Smartphone Telemedicine_A_Novel_Workflow_for_Creating_Prosthetic_Sockets _ Using_Semi-automated_Photogrammetry/12704984/1

[25] E. Strait, "Prosthetics in developing countries," 2006. [Online]. Available: http://citeseerx.ist.psu.edu/viewdoc/download?doi=10.1.1. 551.4255\&rep=rep1\&type=pdf

[26] J. Andrysek, "Lower-Limb Prosthetic Technologies in the Developing World: A Review of Literature from 1994-2010," Prosthetics and Orthotics International, vol. 34, no. 4, pp. 378-398, Dec. 2010. [Online]. Available: http://journals.sagepub.com/doi/10.3109/ 03093646.2010 .520060

[27] S. Laing, N. Lythgo, J. Lavranos, and P. V. S. Lee, "Transtibial Prosthetic Socket Shape in a Developing Country: A study to compare initial outcomes in Pressure Cast hydrostatic and Patella Tendon Bearing designs," Gait \& Posture, vol. 58, pp. 363-368, Oct. 2017. [Online]. Available: https://linkinghub.elsevier.com/retrieve/pii/ S0966636217308524

[28] H. E. J. Meulenbelt, P. U. Dijkstra, M. F. Jonkman, and J. H. B. Geertzen, "Skin problems in lower limb amputees: A systematic review," Disability and Rehabilitation, vol. 28, no. 10, pp. 603-608, Jan. 2006. [Online]. Available: http://www.tandfonline.com/doi/full/ 10.1080/09638280500277032

[29] M. D. Schnell and W. H. Bunch, "Chapter 27: Management of Pain in the Amputee," in Atlas of limb prosthetics: surgical, prosthetic, and rehabilitation principles, 2nd ed. St. Louis: Mosby Year Book, 1992.

[30] B. J. Ranger, M. Feigin, N. Pestrov, Xiang Zhang, V. Lempitsky, H. M. Herr, and B. W. Anthony, "Motion compensation in a tomographic ultrasound imaging system: Toward volumetric scans of a limb for prosthetic socket design," in 2015 37th Annual International Conference of the IEEE Engineering in Medicine and Biology Society (EMBC). Milan: IEEE, Aug. 2015, pp. 7204-7207. [Online]. Available: http://ieeexplore.ieee.org/document/7320054/

[31] Y. Li and R. Brånemark, "Osseointegrated prostheses for rehabilitation following amputation: The pioneering Swedish model," Der Unfallchirurg, vol. 120, no. 4, pp. 285-292, Apr. 2017. [Online]. Available: http://link.springer.com/10.1007/s00113-017-0331-4

[32] D. R. Levinson, "Questionable Billing By Suppliers of Lower Limb Prostheses," Department of Health \& Human Services, Washington, DC, Tech. Rep. OEI-02-10-00170, Aug. 2011. [Online] 
Available: http://www.aopanet.org/wp-content/uploads/2013/12/2011_ CMS_OIGPaymentReport.pdf

[33] B. Rogers, G. W. Bosker, R. H. Crawford, M. C. Faustini, R. R. Neptune, G. Walden, and A. J. Gitter, "Advanced Trans-Tibial Socket Fabrication Using Selective Laser Sintering," Prosthetics and Orthotics International, vol. 31, no. 1, pp. 88-100, Mar. 2007. [Online]. Available: http://journals.sagepub.com/doi/10.1080/ 03093640600983923

[34] D. G. Smith and E. M. Burgess, "The use of CAD/CAM technology in prosthetics and orthotics-current clinical models and a view to the future," Journal of Rehabilitation Research and Development, vol. 38, no. 3, pp. 327-334, Jun. 2001.

[35] J. E. Sanders and M. R. Severance, "Assessment technique for computer-aided manufactured sockets," Journal of Rehabilitation Research and Development, vol. 48, no. 7, pp. 763-774, 2011.

[36] N. E. Walsh, J. L. Lancaster, V. W. Faulkner, and W. E. Rogers, "A Computerized System to Manufacture Prostheses for Amputees in Developing Countries," JPO: Journal of Prosthetics and Orthotics, vol. 1, no. 3, 1989. [Online]. Available: https://journals.lww.com/jpojournal/Fulltext/1989/ 04000/A_Computerized_System_to_Manufacture_Prostheses.11.aspx

[37] D. A. Boone, J. S. Harlan, and E. M. Burgess, "Automated fabrication of mobility aids: review of the AFMA process and VA/Seattle ShapeMaker software design," Journal of Rehabilitation Research and Development, vol. 31, no. 1, pp. 42-49, 1994.

[38] B. Klasson, "Computer aided design, computer aided manufacture and other computer aids in prosthetics and orthotics," Prosthetics and Orthotics International, vol. 9, no. 1, pp. 3-11, Apr. 1985. [Online]. Available: http://journals.sagepub.com/doi/10.3109/ 03093648509164817

[39] M. J. Highsmith, J. T. Kahle, A. Lewandowski, T. D. Klenow, J. J. Orriola, R. M. Miro, O. T. Hill, S. U. Raschke, M. S. Orendurff, J. T. Highsmith, and B. S. Sutton, "ECONOMIC EVALUATIONS OF INTERVENTIONS FOR TRANSTIBIAL AMPUTEES: A SCOPING REVIEW OF COMPARATIVE STUDIES," Technology and innovation, vol. 18, no. 2-3, pp. 85-98, Sep. 2016. [Online]. Available: https://www.ncbi.nlm.nih.gov/pubmed/28066519

[40] E. Normann, A. Olsson, and T.-H. Brodtkorb, "Modular socket system versus traditionally laminated socket: a cost analysis," Prosthetics and Orthotics International, vol. 35, no. 1, pp. 76-80, Mar. 2011. [Online]. Available: http://journals.sagepub.com/doi/10. 1177/0309364610392812

[41] G. Colombo, M. Bertetti, D. Bonacini, and G. Magrassi, "Reverse engineering and rapid prototyping techniques to innovate prosthesis socket design," B. D. Corner, P. Li, and M. Tocheri, Eds., San Jose, CA, Feb. 2006, p. 60560P, 12. [Online]. Available: http://proceedings. spiedigitallibrary.org/proceeding.aspx?doi=10.1117/12.644175

[42] S. Grazioso, M. Selvaggio, and G. Di Gironimo, "Design and development of a novel body scanning system for healthcare applications," International Journal on Interactive Design and Manufacturing (IJIDeM), vol. 12, no. 2, pp. 611-620, May 2018. [Online]. Available: http://link.springer.com/10.1007/s12008-017-0425-9

[43] B. J. Ranger, M. Feigin, X. Zhang, K. M. Moerman, H. Herr, and B. W. Anthony, " $3 \mathrm{D}$ Ultrasound Imaging of Residual Limbs With CameraBased Motion Compensation," IEEE Transactions on Neural Systems and Rehabilitation Engineering, vol. 27, no. 2, pp. 207-217, Feb. 2019. [Online]. Available: https://ieeexplore.ieee.org/document/8624620/

[44] Polhemus, "CASE STUDY: POLHEMUS 3D LASER SCANNER ENABLES PERFECT PROSTHETIC FIT." [Online]. Available: https://polhemus.com/case-study/detail/ hanger-has-revolutionized-the-process-of-fitting-a-patient-for-a-prosthetic

[45] J. E. Sanders, S. B. Mitchell, S. G. Zachariah, and K. Wu, "A digitizer with exceptional accuracy for use in prosthetics research: a technical note," Journal of Rehabilitation Research and Development, vol. 40, no. 2, pp. 191-195, Apr. 2003.

[46] D. M. Sengeh and H. Herr, "A Variable-Impedance Prosthetic Socket for a Transtibial Amputee Designed from Magnetic Resonance Imaging Data:", JPO Journal of Prosthetics and Orthotics, vol. 25, no. 3, pp. 129-137, Jul. 2013. [Online]. Available: http://content.wkhealth.com/linkback/openurl?sid= WKPTLP:landingpage\&an=00008526-201307000-00006

[47] C. Comotti, D. Regazzoni, C. Rizzi, and A. Vitali, "Multimaterial design and 3D printing method of lower limb prosthetic sockets," in Proceedings of the 3rd 2015 Workshop on ICTs for improving Patients Rehabilitation Research Techniques - REHAB '15. Lisbon, Portugal: ACM Press, 2015, pp. 42-45. [Online]. Available: http://dl.acm.org/citation.cfm?doid=2838944.2838955
[48] A. D. Udai and A. N. Sinha, "Processing Magnetic Resonance Images for CAD Model development of Prosthetic Limbs Socket," in 2008 IEEE Region 10 and the Third international Conference on Industrial and Information Systems. Kharagpur, India: IEEE, Dec. 2008, pp. 1-5. [Online]. Available: http://ieeexplore.ieee.org/document/4798343/

[49] A. W. Buis, B. Condon, D. Brennan, B. McHugh, and D. Hadley, "Magnetic resonance imaging technology in transtibial socket research: A pilot study," The Journal of Rehabilitation Research and Development, vol. 43, no. 7, p. 883, 2006. [Online]. Available: http://www.rehab.research.va.gov/jour/06/43/7/pdf/buis.pdf

[50] D. M. Sengeh, K. M. Moerman, A. Petron, and H. Herr, "Multimaterial 3-D viscoelastic model of a transtibial residuum from in-vivo indentation and MRI data," Journal of the Mechanical Behavior of Biomedical Materials, vol. 59, pp. 379-392, Jun. 2016. [Online]. Available: https://linkinghub.elsevier.com/retrieve/pii/] S1751616116000734

[51] G. Colombo, G. Facoetti, and C. Rizzi, "A digital patient for computeraided prosthesis design," Interface Focus, vol. 3, no. 2, p. 20120082, Apr. 2013. [Online]. Available: https://royalsocietypublishing.org/doi/ $10.1098 /$ rsfs.2012.0082

[52] M. Faustini, R. Neptune, R. Crawford, W. Rogers, and G. Bosker, "An Experimental and Theoretical Framework for Manufacturing Prosthetic Sockets for Transtibial Amputees," IEEE Transactions on Neural Systems and Rehabilitation Engineering, vol. 14, no. 3, pp. 304-310, Sep. 2006, 14. [Online]. Available: http: //ieeexplore.ieee.org/document/1703562/

[53] T. Douglas, S. Solomonidis, W. Sandham, and W. Spence, "Ultrasound imaging in lower limb prosthetics," IEEE Transactions on Neural Systems and Rehabilitation Engineering, vol. 10, no. 1, pp. 11-21, Mar. 2002. [Online]. Available: http://ieeexplore.ieee.org/document/ $1021582 /$

[54] O. Ciobanu, W. XU, and G. Ciobanu, "The use of 3D scanning and rapid prototyping in medical engineering," Fiability \& Durability, vol. Supplement no 1, May 2013.

[55] J. P. Spaeth, "Laser Imaging and Computer-Aided Design and Computer-Aided Manufacture in Prosthetics and Orthotics," New Advances in Prosthetics and Orthotics, vol. 17, no. 1, pp. 245-263, Feb. 2006. [Online]. Available: http://www.sciencedirect.com/science/ article/pii/S1047965105001063

[56] B. Chan, J. F. Rudan, P. Mousavi, and M. Kunz, "Intraoperative integration of structured light scanning for automatic tissue classification: a feasibility study," International Journal of Computer Assisted Radiology and Surgery, vol. 15, no. 4, pp. 641649, Apr. 2020. [Online]. Available: http://link.springer.com/10.1007/ s11548-020-02129-8

[57] R. Schmidt, g. coons, V. Chen, T. Gmeiner, and M. Ratto, "3D-printed prosthetics for the developing world," in SIGGRAPH 2015: Studio on - SIGGRAPH '15. Los Angeles, California: ACM Press, 2015, pp. 1-1. [Online]. Available: http://dl.acm.org/citation.cfm?doid=2785585. 2792535

[58] Ohio Willow Wood, "Increasing Efficiency, Repeatability, and Accuracy in Prosthetics and Orthotics Through the Use of CAD," 2006. [Online]. Available: https://www.willowwoodco.com/wp-content/ uploads/2016/04/1951-b-cad-increasing-efficiency-white-paper.pdf

[59] G. Resch, D. R. Southwick, and M. Ratto, "Denaturalizing 3D Printing's Value Claims," in New Directions in Third Wave HumanComputer Interaction: Volume 1 - Technologies, M. Filimowicz and V. Tzankova, Eds. Cham: Springer International Publishing, 2018, pp. 105-122. [Online]. Available: https://doi.org/10.1007/ 978-3-319-73356-2_7

[60] P. Zanuttigh, G. Marin, C. Dal Mutto, F. Dominio, L. Minto, and G. M. Cortelazzo, Time-of-Flight and Structured Light Depth Cameras Technology and Applications. Cham: Springer International Publishing, 2016, oCLC: 1050006121

[61] W. Linder, Digital Photogrammetry. Berlin, Heidelberg: Springer Berlin Heidelberg, 2016. [Online]. Available: http:/llink.springer.com/ 10.1007/978-3-662-50463-5

[62] R. Hartley and A. Zisserman, Multiple view geometry in computer vision, 2004, oCLC: 171123855. [Online]. Available: https://doi.org/ 10.1017/CBO9780511811685

[63] Z. An, "Accuracy Assessment of 3D Point Clouds Generated by Photogrammetry From Different Distances," Jan. 2017.

[64] R. Salazar-Gamarra, R. Seelaus, J. V. L. da Silva, A. M. da Silva, and L. L. Dib, "Monoscopic photogrammetry to obtain 3D models by a mobile device: a method for making facial prostheses," Journal of Otolaryngology - Head \& Neck Surgery, vol. 45, no. 1, p. 33, 
Dec. 2016. [Online]. Available: http://journalotohns.biomedcentral. com/articles/10.1186/s40463-016-0145-3

[65] A. Hernandez and E. Lemaire, "A smartphone photogrammetry method for digitizing prosthetic socket interiors," Prosthetics and Orthotics International, vol. 41, no. 2, pp. 210-214, Apr. 2017. [Online]. Available: http://journals.sagepub.com/doi/10.1177/ 0309364616664150

[66] R. B. Taqriban, R. Ismail, M. Ariyanto, and A. F. Yaya Syah Putra, "3D Model of Photogrammetry Technique for Transtibial Prosthetic Socket Design Development," in 2019 International Seminar on Research of Information Technology and Intelligent Systems (ISRITI), Dec. 2019, pp. 456-461, journal Abbreviation: 2019 International Seminar on Research of Information Technology and Intelligent Systems (ISRITI).

[67] I. Barbero-García, M. Cabrelles, J. L. Lerma, and MarquésMateu, "Smartphone-based close-range photogrammetric assessment of spherical objects," The Photogrammetric Record, vol. 33, no. 162, pp. 283-299, Jun. 2018. [Online]. Available: http: //doi.wiley.com/10.1111/phor.12243

[68] P. Ajjimaporn, D. Feist, J. Straub, and S. Kerlin, "Impact of lighting and attire on 3D scanner performance," B. Javidi and J.-Y. Son, Eds., Baltimore, Maryland, United States, May 2015, p. 94951E. [Online]. Available: http://proceedings.spiedigitallibrary.org/ proceeding.aspx?doi=10.1117/12.2176708

[69] D. Solav, K. M. Moerman, A. M. Jaeger, and H. M. Herr, "A Framework for Measuring the Time-Varying Shape and FullField Deformation of Residual Limbs Using 3-D Digital Image Correlation," IEEE Transactions on Biomedical Engineering, vol. 66, no. 10 , pp. 2740-2752, Oct. 2019, 32. [Online]. Available: https://ieeexplore.iee.org/document/8625546/

[70] G. Colombo, S. Filippi, C. Rizzi, and F. Rotini, "A new design paradigm for the development of custom-fit soft sockets for lower limb prostheses," Computers in Industry, vol. 61, no. 6, pp. 513-523, Aug. 2010. [Online]. Available: https: ///inkinghub.elsevier.com/retrieve/pii/S0166361510000254

[71] M. Buzzi, G. Colombo, G. Facoetti, S. Gabbiadini, and C. Rizzi, "3D modelling and knowledge: tools to automate prosthesis development process," International Journal on Interactive Design and Manufacturing (IJIDeM), vol. 6, no. 1, pp. 41-53, Feb. 2012. [Online]. Available: http://link.springer.com/10.1007/s12008-011-0137-5

[72] J. W. Steer, P. A. Grudniewski, M. Browne, P. R. Worsley, A. J. Sobey, and A. S. Dickinson, "Predictive prosthetic socket design: part 2-generating person-specific candidate designs using multi-objective genetic algorithms," Biomechanics and Modeling in Mechanobiology, Nov. 2019. [Online]. Available: https://doi.org/10. 1007/s10237-019-01258-7

[73] J. W. Steer, P. R. Worsley, M. Browne, and A. S. Dickinson, "Predictive prosthetic socket design: part 1-population-based evaluation of transtibial prosthetic sockets by FEA-driven surrogate modelling," Biomechanics and Modeling in Mechanobiology, Jun. 2019. [Online]. Available: https://doi.org/10.1007/s10237-019-01195-5

[74] S. Li, H. Lan, X. Luo, Y. Lv, L. Gao, and H. Yu, "Quantitative compensation design for prosthetic socket based on eigenvector algorithm method," Review of Scientific Instruments, vol. 90, no. 10, p. 104101, Oct. 2019. [Online]. Available: http://aip.scitation.org/doi/ $10.1063 / 1.5092743$

[75] M. H. Michalski and J. S. Ross, "The Shape of Things to Come: 3D Printing in Medicine," JAMA, vol. 312, no. 21, p. 2213, Dec. 2014, 4. [Online]. Available: http://jama.jamanetwork.com/article.aspx?doi=10. 1001/jama.2014.9542

[76] C. Lunsford, G. Grindle, B. Salatin, and B. E. Dicianno, "Innovations With 3-Dimensional Printing in Physical Medicine and Rehabilitation: A Review of the Literature," $P M \& R$, vol. 8, no. 12, pp. 1201-1212, Dec. 2016. [Online]. Available: http: //doi.wiley.com/10.1016/j.pmrj.2016.07.003

[77] K.-T. Nguyen, L. Benabou, and S. Alfayad, "Systematic Review of Prosthetic Socket Fabrication using 3D printing," in Proceedings of the 2018 4th International Conference on Mechatronics and Robotics Engineering - ICMRE 2018. Valenciennes, France: ACM Press, 2018, pp. 137-141. [Online]. Available: http://dl.acm.org/citation.cfm? doid=3191477.3191506

[78] L. H. Hsu, G. F. Huang, C. T. Lu, D. Y. Hong, and S. H. Liu, "The Development of a Rapid Prototyping Prosthetic Socket Coated with a Resin Layer for Transtibial Amputees," Prosthetics and Orthotics International, vol. 34, no. 1, pp. 37-45, Mar. 2010. [Online]. Available: http://journals.sagepub.com/doi/10.3109/03093640902911820

[79] Z. Shi, Y. Peng, and W. Wei, "Recent Advance on Fused Deposition Modeling," Recent Patents on Mechanical
Engineering, vol. 7, no. 2, pp. 122-130, Jul. 2014. [Online]. Available: http://www.eurekaselect.com/openurl/content.php? genre $=$ article $\&$ issn $=2212-7976 \&$ volume $=7 \&$ issue $=2 \&$ spage $=122$

[80] M. J. Gerschutz, M. L. Haynes, D. Nixon, and J. M. Colvin, "Strength evaluation of prosthetic check sockets, copolymer sockets, and definitive laminated sockets," The Journal of Rehabilitation Research and Development, vol. 49, no. 3, p. 405, 2012, 20. [Online]. Available: http://www.rehab.research.va.gov/jour/2012/493/pdf/gershutz493.pdf

[81] J. C. H. Goh, P. V. S. Lee, and P. Ng, "Structural integrity of polypropylene prosthetic sockets manufactured using the polymer deposition technique," Proceedings of the Institution of Mechanical Engineers, Part H: Journal of Engineering in Medicine, vol. 216, no. 6, pp. 359-368, Jun. 2002, 18. [Online]. Available: http://journals.sagepub.com/doi/10.1243/095441102321032157

[82] T. A. Current, G. F. Kogler, and D. G. Earth, "Static structural testing of trans-tibial composite sockets," Prosthetics and Orthotics International, vol. 23, no. 2, pp. 113-122, Aug. 1999, 17. [Online]. Available: http://journals.sagepub.com/doi/10.3109/03093649909071622

[83] I. A. Cabrera, J. Martin, S. T. Fong, K. H. M. Nguyen, V. D. Bourgin, W.-Y. Zhao, K. J. Lawson, K. A. Wong, P. Bagheri, P. J. Hill, B. M. Henning, P. Castillo, R. R. Rao, M. A. Meyers, A. Y. Lin, and J. M. McKittrick, "Seeing the Big Picture: Improving The Prosthetic Design Cycle Using $360^{\circ} 3 \mathrm{D}$ Digital Image Correlation," preprint, Jul. 2020. [Online]. Available: https://www. techrxiv.org/articles/Seeing_the_Big_Picture_Improving_The_Prosthetic_Design_Cycle_Using_360_3D_Digital_Image_Correlation/12705722/1

[84] J. S. Rovick, D. S. Childress, and R. Chan, "An additive fabrication technique for the cam of prosthetic sockets," The Department of Veterans Affairs, Tech. Rep., 1995.

[85] N. Herbert, D. Simpson, W. D. Spence, and W. Ion, "A preliminary investigation into the development of 3-D printing of prosthetic sockets," Journal of Rehabilitation Research and Development, vol. 42, no. 2, pp. 141-146, Apr. 2005.

[86] P. Lee, K. C. Tan, K. F. Tam, and S. L. Lye, "Biomechanical evaluation of prosthetic sockets fabricated using fused depository method," in 4th Asian Symposium on Biomedical Materials, Singapore, 1998.

[87] B. Rogers, A. Gitter, G. Bosker, M. Faustini, M. Lokhande, and R. Crawford, "Clinical Evaluation of Prosthetic Sockets Manufactured by Selective Laser Sintering 505," in 2001 International Solid Freeform Fabrication Symposium, 2001.

[88] B. Rogers, S. Stephens, A. Gitter, G. Bosker, and R. Crawford, "Double-Wall, Transtibial Prosthetic Socket Fabricated Using Selective Laser Sintering: A Case Study," JPO: Journal of Prosthetics and Orthotics, vol. 12, no. 3, 2000. [Online]. Available: https://journals.lww.com/jpojournal/Fulltext/2000/ 12030/Double_Wall,_Transtibial_Prosthetic_Socket.7.aspx

[89] A. Soleimani-Gorgani, "Inkjet Printing," in Printing on Polymers. Elsevier, 2016, pp. 231-246. [Online]. Available: https://linkinghub. elsevier.com/retrieve/pii/B9780323374682000142

[90] S. Ali, N. A. Abu Osman, A. Eshraghi, H. Gholizadeh, N. A. b. Abd razak, and W. A. B. B. Wan Abas, "Interface pressure in transtibial socket during ascent and descent on stairs and its effect on patient satisfaction," Clinical Biomechanics, vol. 28, no. 9-10, pp. 994-999, Nov. 2013. [Online]. Available: https: ///linkinghub.elsevier.com/retrieve/pii/S0268003313002106

[91] E. Al-Fakih, N. Abu Osman, and F. Mahmad Adikan, "Techniques for Interface Stress Measurements within Prosthetic Sockets of Transtibial Amputees: A Review of the Past 50 Years of Research," Sensors, vol. 16, no. 7, p. 1119, Jul. 2016. [Online]. Available: http://www.mdpi.com/1424-8220/16/7/1119

[92] G. Papaioannou, C. Mitrogiannis, G. Nianios, and G. Fiedler, "Assessment of amputee socket-stump-residual bone kinematics during strenuous activities using Dynamic Roentgen Stereogrammetric Analysis," Journal of Biomechanics, vol. 43, no. 5, pp. 871-878, Mar. 2010. [Online]. Available: https://linkinghub.elsevier.com/retrieve/pii/ S0021929009006496

[93] P. Dou, X. Jia, S. Suo, R. Wang, and M. Zhang, "Pressure distribution at the stump/socket interface in transtibial amputees during walking on stairs, slope and non-flat road," Clinical Biomechanics, vol. 21 , no. 10, pp. 1067-1073, Dec. 2006. [Online]. Available: https://linkinghub.elsevier.com/retrieve/pii/S026800330600129X

[94] E. C. Swanson, J. B. McLean, K. J. Allyn, C. B. Redd, and J. E. Sanders, "Instrumented socket inserts for sensing interaction at the limb-socket interface," Medical Engineering \& Physics, vol. 51, pp. 111-118, Jan. 2018. [Online]. Available: https://linkinghub.elsevier.com/retrieve/pii/S1350453317302953 
[95] L. Paternò, M. Ibrahimi, E. Gruppioni, A. Menciassi, and L. Ricotti, "Sockets for Limb Prostheses: A Review of Existing Technologies and Open Challenges," IEEE Transactions on Biomedical Engineering, vol. 65 , no. 9, pp. 1996-2010, Sep. 2018

[96] B. Lin, K. M. Moerman, C. G. McMahan, K. A. Pasch, and H. M. Herr, "Low-Cost Methodology for Skin Strain Measurement of a Flexed Biological Limb." IEEE transactions on bio-medical engineering, vol. 64, no. 12, pp. 2750-2759, Dec. 2017, place: United States.

[97] D. Solav, K. M. Moerman, A. M. Jaeger, K. Genovese, and H. M. Herr, "MultiDIC: An Open-Source Toolbox for Multi-View 3D Digital Image Correlation," IEEE Access, vol. 6, pp. 30520-30535, 2018. [Online]. Available: https://ieeexplore.ieee.org/document/8371235/

[98] H. Gholizadeh, N. A. Abu Osman, G. Lúvíksdóttir, A. Eshraghi, M. Kamyab, and W. A. B. Wan Abas, "A new approach for the pistoning measurement in transtibial prosthesis," Prosthetics and Orthotics International, vol. 35, no. 4, pp. 360-364, Dec. 2011. [Online]. Available: http://journals.sagepub.com/doi/10.1177/ 0309364611423130

[99] A. Dickinson, J. Steer, and P. Worsley, "Finite element analysis of the amputated lower limb: A systematic review and recommendations," Medical Engineering \& Physics, vol. 43, pp. 1-18, May 2017, 6. [Online]. Available: https://linkinghub.elsevier.com/retrieve/pii/S1350453317300607

[100] I. Ali, R. Kumar, and Y. Singh, "Finite Element Modelling and Analysis of Trans-Tibial Prosthetic Socket Finite Element Modelling and Analysis of Trans-Tibial Prosthetic Socket," Global Journal of Researches in Engineering: A Mechanical and Mechanics Engineering, vol. 14, pp. 42-50, Sep. 2014, 13

[101] J. C. Cagle, P. G. Reinhall, K. J. Allyn, J. McLean, P. Hinrichs, B. J. Hafner, and J. E. Sanders, "A finite element model to assess transtibial prosthetic sockets with elastomeric liners," Medical \& Biological Engineering \& Computing, vol. 56, no. 7, pp. 12271240, Jul. 2018. [Online]. Available: http://link.springer.com/10.1007/ s11517-017-1758-z

[102] M. C. Faustini, R. R. Neptune, and R. H. Crawford, "The quasi-static response of compliant prosthetic sockets for transtibial amputees using finite element methods," Medical Engineering \& Physics, vol. 28, no. 2, pp. 114-121, Mar. 2006. [Online]. Available: https://linkinghub.elsevier.com/retrieve/pii/S1350453305001013

[103] M. S. Jamaludin, A. Hanafusa, Y. Shinichirou, Y. Agarie, H. Otsuka and K. Ohnishi, "Analysis of Pressure Distribution in Transfemoral Prosthetic Socket for Prefabrication Evaluation via the Finite Element Method," Bioengineering, vol. 6, no. 4, p. 98, Oct. 2019, 7. [Online]. Available: https://www.mdpi.com/2306-5354/6/4/98

[104] R. Surapureddy, S. Stagon, A. Schönning, and A. Kassab, "Predicting pressure distribution between transfemoral prosthetic socket and residual limb using finite element analysis," International Journal of Experimental and Computational Biomechanics, vol. 4, no. 1, p. 32, 2016, 16. [Online]. Available: http://www.inderscience.com/link.php? id=10002681

[105] L. Van, S. Yamamoto, and A. Hanafusa, "Finite Element Analysis for Quantitative Evaluation of a Transfemoral Prosthesis Socket for Standing Posture," International Journal of Computer Applications, vol. 170, no. 1, pp. 1-8, Jul. 2017, 9. [Online]. Available: http://www.ijcaonline.org/archives/volume170/ number1/tuan-2017-ijca-914658.pdf

[106] A. van Heesewijk, A. Crocombe, S. Cirovic, M. Taylor, and W. Xu, "Evaluating the Effect of Changes in Bone Geometry on the Trans-femoral Socket-Residual Limb Interface Using Finite Element Analysis," in World Congress on Medical Physics and Biomedical Engineering 2018, L. Lhotska, L. Sukupova, I. Lacković, and G. S. Ibbott, Eds. Singapore: Springer Singapore, 2019, vol. 68/2, pp. 587-591, 15 Series Title: IFMBE Proceedings. [Online]. Available: http://link.springer.com/10.1007/978-981-10-9038-7_109

[107] X. Jia, M. Zhang, and W. C. Lee, "Load transfer mechanics between trans-tibial prosthetic socket and residual limb-dynamic effects," Journal of Biomechanics, vol. 37, no. 9, pp. 1371-1377, Sep. 2004. [Online]. Available: https://linkinghub.elsevier.com/retrieve/pii/ S0021929003004871

\section{APPENDIX}

\section{A. Proposed Research Avenues for a Virtual Healthcare} Solution

It is clear that a great deal of research is still required to make a low cost system for the manufacturing and distribution of prosthetic sockets. While previous work has focused on technologies that can be utilized within the clinic, more digital tools need to be developed in order to facilitate a workflow outside of the clinical environment. These tools should allow amputees to scan their residual limbs and interact with clinicians remotely. In addition, these tools should enable automated digital socket rectification to reduce the labor cost of designing prosthetic sockets. Finally, the AM materials currently used for prosthetic sockets do not meet the ISO 10328 standard. Thus, researchers should find ways to improve the material properties of these polymers at a low cost to enable remote prosthetic manufacturing.

Although it has not been studied intensively in the past, photogrammetry technology should be studied and utilized for building limb models. Photogrammetry currently requires a great deal of work to generate accurate 3D models. However, automated photogrammetric tools for limb scanning could significantly reduce the amount of work required to generate 3D models. This technology holds promise for low cost limb scanning specifically because it can be integrated into a smartphone application. Although many other technologies have not penetrated the developing world, cell phones are readily accessible and could facilitate both the interaction between clinician and patient as well as the transfer of limb scans via mobile cloud services.

Previous work on automated socket rectification was preliminary, but there stands a great opportunity to utilize advancements in the field of computer science to improve the feasibility of an automated socket rectification system. Specifically, an algorithm that could read the 3D geometric information from a scanned limb and infer the predicted ideal socket geometry would be groundbreaking. It is important that this algorithm learns from quantitative examples of successfully rectified sockets to improve its predictive abilities instead of utilizing overly prescriptive methods from clinical practice. This algorithm must be implemented into a CAD program to be able to visualize and manipulate the final predictive geometry.

Equally important to the other technologies, we need to improve the properties of AM materials utilized for prosthetic sockets. FDM was the most affordable and accessible AM method for making prosthetic sockets, but the materials currently available are mechanically insufficient. It would be a large task to synthesize a new polymer chemistry that is capable of being manufactured with FDM, at a low cost, and without adverse environmental effects. A simpler route to explore in the near future is to reinforce AM prosthetic sockets externally using a polymer composite or structural reinforcement strategies such as bioinspiration.

Enabling the automated manufacture of prosthetic sockets at a low cost would have a significant positive impact on the accessibility and quality of amputee healthcare. These technologies can dramatically improve the quality of life for amputees by providing mobility to people who currently do not have access to prosthetic care. They will also help amputees who have stopped wearing their prostheses because of ill-fit by giving them an affordable avenue for replacement. Digital healthcare technologies have the potential to reach the millions 
of amputees in underserved communities. Affordable access to prosthetic care will undoubtedly give these amputees a new lease on life.

\section{B. Prostheses as Social Mobility Devices}

Often, traditional beliefs cause community discrimination against people with disabilities. This led to mental health problems for amputees in Sierra Leone. They reported being mocked, dehumanized, marginalized from society, and even discouraged from educational pursuits [5]. Stigmas against disability limit access to employment, medical treatment, transportation, and other essential aspects of life.

Societal responses to disability indicate that there is not only a need for more clinical support, but also a need for education on disabilities and the rights of disabled people. Empowering amputees with affordable prostheses has the potential to reduce discrimination, increase an amputee's acceptance in society, and give them freedom, dignity, and purpose through mobility.

Many nonprofit and government organizations are working to address the lack of support for rehabilitation services in lowincome countries. Although specialized international organizations have the potential to make a large impact, humanitarian initiatives require extensive financial and technical support that cannot always be provided due to time and resource limitations. Long-term results require the integration of novel solutions into national systems. Sustainable change involves professional training, national policy development, materials and equipment, and other investments of time and money [1]. Funding is lacking not only for amputees seeking care, but also for nonprofits aiming to address their needs [3]. Without adequate financial support for these organizations, clinicians must raise service fees to support their work. Funding limitations limit access, exclude those in need, and contribute to cycles of poverty [1].

\section{Guidelines for the Design and Implementation of Prosthetic Care}

It is clear that limb prostheses can have a dramatic positive impact on an amputee's life. A thorough understanding of the current system is needed to design innovative solutions and address gaps in accessibility. To develop a novel healthcare system, engineers must ask: What exactly must these prostheses achieve in their lifetime? How are prostheses currently manufactured? How are the current limitations of limb prosthetics addressed in clinical practice?

The World Health Organization lists a significant number of guidelines that prosthetic devices must meet. When interfacing with a patient, a prosthetic device must:

"be comfortable, with a well-adapted interface between the body segment and the device; be functional; be easy to put on and remove; not endanger user safety; be durable; have the best possible cosmetic appearance [...]; be biocompatible[...]; not be too heavy [...]; be acceptable by and adaptable to the majority of users [...]; be culturally appropriate [...]; suit the climate; suit the local terrain; and suit local working conditions." [1]
Furthermore, the WHO explains that prosthetics must be safe:

"Technologies and working methods should be of proven, documented efficacy and safety; Technologies and working methods should adhere to international standards. [...]; Products should be durable and have a long lifespan; Products should be easily adjusted, maintained and repaired (as far as possible by the users themselves); [...]; Working methods should not be hazardous to personnel [...]" [1]

Most importantly, prosthetics must be affordable:

"Products should be affordable by the system and/or the individual; Technologies should be cost-effective [...] allow for rationalization of production methods and swift fabrication; not require many tools and machines or very advanced, expensive equipment; require low service maintenance; generate minimum waste; and made of readily available components and materials[...] Prosthetists and orthotists should have sufficient skill and knowledge to apply technologies and working methods; if this is not the case, training must be practically feasible and affordable[...]" [1]

These requirements highlight the complexity of building low cost prosthetics. All of these guidelines should be considered and respected when delivering prosthetic care. The priority of each should be tailored to each specific setting: high vs. low income countries; various amputee backgrounds; and different clinic capabilities.

\section{Notes on Additive Manufacturing for Building Custom Prostheses}

Computer technology has the potential to improve digital prosthetic manufacturing. By automating fabrication, virtual workflows decrease the need for patient participation and increase production efficiency [78]. CAM methods are generally more consistent than traditional processes, since production does not depend as much on prosthetist experience [15]. However, manufacturing advancements were restricted by material constraints.To achieve the desired level of quality, materials need to provide sufficient strength and durability. Because of this limitation, CAD models were only used as references and the sockets were built using traditional fabrication processes [34].

Additive manufacturing technology has the potential to overcome these historical obstacles. Instead of using a plaster or foam positive mold as a template for traditional fabrication, additive manufacturing builds prosthetic sockets directly. A key benefit of additive manufacturing is that geometric complexity does not increase production cost. Furthermore, since the process is automated, multiple sockets can be manufactured simultaneously [33]. Compared to traditional methods, additive manufacturing broadens the range of available materials [47]. However, most of these materials are still not sufficiently durable for prosthetic socket applications. 3D printed materials tend to be heavier than traditional ones and result in a lower factor of safety [46]. 